\title{
Distortions of National Policies to Renewable En- ergy Cooperation Mechanisms
}

Jelle Meus, Hanne Pittomvils, Stef Proost, Erik Delarue

Pre-print paper accepted for publication in The Energy Journal:

Meus, J., Pittomvils, H., Proost, S., and Delarue, E. (2022). "Distortions of National Policies to Renewable Energy Cooperation Mechanisms" Energy Journal 43(3): 69-100 doi:10.5547/01956574.43.4.jmeu.

Last update: April 17, 2021

All working papers, including the latest version of this paper, may be downloaded from: www.mech.kuleuven.be/en/tme/research/energy-systems-integration-modeling 


\title{
Distortions of National Policies to Renewable Energy Cooperation Mechanisms
}

\author{
Jelle Meus ${ }^{a, b}$, Hanne Pittomvils ${ }^{a}$, Stef Proost ${ }^{c}$, and Erik Delarue ${ }^{a, b, *}$
}

\begin{abstract}
The EU endeavors to stimulate the use of renewable energy cooperation mechanisms. These cooperation mechanisms can significantly reduce the policy cost for meeting renewable targets. Several authors, however, have raised concerns that such cooperation mechanisms can be subject to efficiency losses due to different national regulatory conditions, and due to an ill-advised selection of cross-border support instruments. A quantitative evaluation of these effects remains missing. To address this gap, we first introduce a unifying analytical framework to show how optimal cross-border renewable energy trade should be organized and how these mechanisms could be distorted. We then develop a partial equilibrium model, formulated as a large-scale mathematical program with equilibrium constraints, to assess the impact of (i) different national grid cost allocation regimes and (ii) different cross-border feed-in premium implementations. Our results indicate that EU-wide auctions for renewable electricity should (i) not be based on sliding feed-in premiums and should (ii) ideally be discriminatory if national regulatory conditions differ across Member States. We also consider country-level distributional effects and confirm that Member States can lose when engaging in renewable cooperation.
\end{abstract}

Keywords: Energy policy, Renewable electricity, Grid connection charges, Renewable energy cooperation mechanisms

http://dx.doi.org/

C61, D47, D61, H23, Q48

\section{INTRODUCTION}

The European Union is committed to reach a $20 \%$ share for renewables in final energy consumption by 2020 , and at least a $32 \%$ share by 2030 . The achievement of these EU-wide quotas is secured by assigning differentiated national targets for each of the Member States. For the 2020-target allocation, the European Council has adopted mandatory targets mostly based on GDP per capita (EU, 2009). Wealthier countries are subject to higher targets and therefore have to contribute more. Although such an allocation scheme might be considered fair, it is highly inefficient since it does not take into account the varying renewable energy (RES) resource potential among the Member States (D'haeseleer et al., 2017). Properly setting the national targets would greatly reduce the compliance cost for meeting the RES quota ${ }^{1}$.

For the 2030 EU-wide target, the national allocation scheme has been updated. The European Commission established the Energy Governance Regulation, through which they aim to reach a set of

${ }^{a}$ KU Leuven, Division of Applied Mechanics and Energy Conversion, Celestijnenlaan 300 box 2421, 3001 Heverlee, Belgium ${ }^{b}$ EnergyVille, Thor Park, Poort Genk 8310, B-3600 Genk, Belgium

${ }^{c}$ KU Leuven, Department of Economics, Naamsestraat 69, 3000 Leuven, Belgium

${ }^{*}$ Corresponding author. E-mail: erik.delarue@kuleuven.be.

\footnotetext{
${ }^{1}$ This statement has been extensively validated in the academic literature, see e.g. Voogt and Uyterlinde (2006); Ragwitz et al. (2007); Capros et al. (2011); Aune et al. (2012); Jägemann et al. (2013); Unteutsch and Lindenberger (2014); Saguan and Meeus (2014); Green et al. (2016); Perez et al. (2016). For additional economic rationales for renewable energy trading, we refer to Busch and Ortner (2019) and Von Blüchen et al. (2019).
} 
voluntary national contributions which collectively satisfy the EU-wide quota (EU, 2018b). By the end of 2018, each Member State had to submit their 2030 RES goals via their draft national renewable energy and climate plan (NECP). The Commission then issued recommendations to Member States whose contributions it deemed insufficient. All of this has led to the final NECPs which had to be submitted at the end of 2019 and comprise specific national RES ambitions. These targets are thus based on national initiatives and a political bargaining procedure instead of economic and resource potential considerations, which is why the 2030 target distribution is unlikely to be cost-effective.

The EU intended to alleviate this issue by introducing a legal framework for the use of renewable cooperation mechanisms (EU, 2009; Klessmann et al., 2014). Such mechanisms, if designed and used properly, allow to approximate the most cost-effective distribution of renewable energy across the Member States whilst the distributional effects from the national quotas still apply (i.e. wealthy or more ambitious countries contribute more). Member States can employ statistical transfers, implement joint projects and set up joint support schemes. Statistical transfers allow for RES production in one Member State to be virtually transferred to the RES statistics of another Member State. The over-complying Member State is then financially compensated by the RES-importing Member State. Joint projects are developed under framework conditions set by the participating Member states (e.g. creating an allocation rule for the generated renewable energy). By setting up joint support schemes, Member States can merge or coordinate their RES support policies.

Towards 2030, the EU introduced two additional cooperation possibilities: the Union renewable development platform (URDP) and the Union renewable energy financing mechanism (URFM). The URDP resembles a centralized market for statistical transfers whereas up till now only bilateral agreements were possible (EU, 2018b). The URFM collects voluntary contributions from the individual Member States used to tender support for new renewable energy projects in the entire Union (EU, 2018a). The renewable energy generated by the installations financed via this mechanism will be statistically attributed to the participating Member States, reflecting their relative payments.

This paper is dedicated to the distortions of national policies to these mechanisms. We concentrate on renewable electricity (RES-E) promotion and cooperation, although the main concepts are applicable to RES cooperation in general. Ecofys and eclareon (2018) raise the concern that renewable cooperation mechanisms can be subject to efficiency losses due to different national regulatory conditions. RES-E project developers in different Member States face diverse regulations on grid connection financing regimes, planning and permitting procedures, etc. These regulatory differences may impede establishing an EU-wide level playing field. Instead of being distributed based on efficiency grounds, RES capacity might become biased towards Member States with favorable regulatory conditions. Moreover, Meus et al. (2019) show that the performance of EU-wide auctions for renewable electricity may be very sensitive towards the type of support instrument that is being used. In their stylized case-study, suboptimal cross-border support instruments can actually perform worse than no cooperation at all.

Our contribution is twofold. First, we develop a unifying analytical framework to show how optimal cross-border renewable energy trade should be organized and how these mechanisms could be distorted. The framework is sufficiently general to encapsulate all different cooperation mechanisms and to reveal the market-implications of the distortions discussed above. Second, we aim to quantitatively evaluate the importance of these distortions. To this end, we develop a partial equilibrium model, formulated as a large-scale mathematical program with equilibrium constraints, to assess the impact of (i) different national grid cost allocation regimes and (ii) different cross-border feed-in premium implementations (i.e. the fixed- and the sliding feed-in premium). The model is then applied to a case study that examines cooperation in onshore wind energy among France, Germany, the Netherlands and Belgium. Apart from global welfare implications, we also consider country-level distributional implications.

The remainder of this paper is structured as follows. Section 2 situates our contribution in the literature and briefly introduces the main idea behind (i) grid cost allocation regimes and (ii) various 
feed-in premium implementations. Section 3 introduces the analytical framework which illustrates how regulatory conditions can distort renewable energy cooperation mechanisms. The section additionally illustrates how cross-border cooperation based on the sliding feed-in premium can perform suboptimal. Sections 4 and 5 respectively introduce the model and case set-up. Section 6 presents the main results, whereas additional results are provided in the Appendix. Section 7 concludes.

\section{LITERATURE REVIEW}

Literature on renewable cooperation mechanisms can roughly be classified into three strands. The first strand aims to explain the few implementations of these mechanisms by understanding the barriers to engage in renewable trade. Indeed, the adoption of cooperation mechanisms has been limited in spite of the strong prospects of cooperation. Norway and Sweden have implemented a joint tradable green certificate market, Germany and Denmark organized pilot auctions for photovoltaics capacity open to investors in both Member States, the Netherlands will be importing statistical transfers from Denmark, and Luxemburg will be importing statistical transfers from both Estonia and Lithuania (Klessmann et al., 2014; Caldés et al., 2018; Rijksoverheid, 2020). Both Klessmann et al. (2014) and Klinge Jacobsen et al. (2014) introduce and categorize a set of cooperation barriers. Unteutsch (2014) first showed that coupling tradable green certificate markets can introduce interand intra-country distributional concerns. This result later has been extended to the general use of cooperation mechanisms by Meus et al. (2019). Caldés et al. (2018) rank the importance of several barriers based on a dedicated survey. Finally, Busch and Ortner (2019) propose a new cooperation mechanism that is designed to mitigate some of these barriers.

The second strand estimates the economic benefit of renewable cooperation. These studies generally employ a centralized EU-wide single-objective optimization model and estimate the policy cost of meeting renewable targets when subject to (i) national targets and (ii) one single EU target. The cost difference between these scenarios can then be interpreted as the potential economic gain of renewable trade. Depending on the scenarios, these studies conclude that the compliance cost for meeting RES-targets can roughly be reduced by $30 \%-50 \%$ when fully engaging in renewable cooperation (Voogt and Uyterlinde, 2006; Ragwitz et al., 2007; Capros et al., 2011; Aune et al., 2012; Jägemann et al., 2013; Unteutsch and Lindenberger, 2014; Saguan and Meeus, 2014; Green et al., 2016; Perez et al., 2016). Perez et al. (2016) additionally show that most of these benefits can be captured by only limitedly cooperating.

Although these optimization studies are invaluable to reveal the prospects for renewable cooperation, they are not able to capture the underlying market dynamics. In reality, market imperfections can redirect the distribution of renewable capacity away from the optimum. The third strand of literature therefore analyzes how cooperation mechanisms can be distorted. Ecofys and eclareon (2018) raise the concern that different national regulatory conditions may prohibit the efficient use of cooperation mechanisms. RES-E project developers in different Member States typically face diverse regulations on grid connection financing regimes, financing conditions, planning and permitting procedures, etc. These differences may impede establishing an EU-wide level playing field. The authors therefore conclude that regulatory conditions should converge, or that these should be properly dealt with when designing cross-border cooperation mechanisms. Furthermore, Meus et al. (2019) assess the performance of different support instruments in the context of EU-wide auctions for renewable electricity. The authors conclude that fixed feed-in premium systems are optimal and that significant welfare losses might occur if cross-border auctions would be based on a different instrument.

Both studies do raise important concerns, but were only exploratory in nature. The study of Ecofys and eclareon (2018) estimates how regulatory differences affect the levelized cost of electricity of onshore wind, but does not comprehensively consider the market implications. The study of Meus et al. (2019) aimed to obtain theoretical insights via a stylized example, but a quantitative evaluation 
of the actual welfare effects remains missing. We aim to contribute by quantifying the distortions caused by (i) different national grid cost allocation regimes and (ii) different cross-border feed-in premium implementations. The remainder of this section briefly introduces both these causes.

Grid connection charges are the payments made by RES project developers to the transmission system operator (TSO) for connecting their installation to the grid. The literature generally distinguishes between shallow and deep connection charges (Bjørnebye et al., 2018). Shallow connection charges just cover the cost for connecting the generator to the nearest substation. Deep connection charges additionally include any network reinforcement costs required to accommodate the new capacity. It is well-understood that shallow connection charges tend to promote inefficient locations because grid costs are not completely internalized. Then again, deep connection charges encounter difficulties concerning how reinforcement costs are to be shared among new and existing users. The trade-off between shallow and deep grid connection charges has been covered extensively in the literature (Turvey, 2006; Olmos and Pérez-Arriaga, 2009), as well as the interaction between renewable subsidies and connection charges (Bjørnebye et al., 2018; Wagner, 2019). To the authors' knowledge, however, the consideration of non-harmonized connection charging regimes in the context of cross-border RES cooperation has not yet been researched, even though connection regimes are certainly not harmonized in the EU (Anselm et al., 2020; ENTSO-E, 2019).

We furthermore consider two possible feed-in premium implementations: the fixed feed-in premium (FFIP) and the sliding feed-in premium (SFIP). The FFIP grants renewable generators a fixed payment on top of the electricity price. The SFIP resembles the FFIP, but the premium paid on top of the electricity price varies per time block (e.g. monthly) and is calculated as the difference between a fixed strike price (which is the support level), and the average electricity price during that block. Furthermore, if the average electricity price exceeds the fixed strike price, the premium is usually set to zero and thus cannot be negative. For more information on the actual implementations, we refer to Huntington et al. (2017).

The FFIP is theoretically an optimal instrument to satisfy renewable energy targets in a deterministic context (Pahle et al., 2016). The main advantage that sliding systems hold over fixed premiums is investment risk reduction (Winkler et al., 2016; CEER, 2016). By recalibrating the premium level during every block based on mean electricity prices, investors are shielded from long-term price trends since the mean remuneration will always at least equal the strike price. This eliminates long-term price uncertainty, reduces risk and thereby also the financing costs. Furthermore, Meus et al. (2021) show that investment incentives under sliding and fixed premium systems are very much alike when the systems are implemented within a uniformly-priced Member State. The SFIP is thus able to reduce financing costs without compromising allocative efficiency. This likely is the main reason why most Member States currently subsidize new RES-E generation via sliding feed-in systems (Benja et al., 2017). As mentioned earlier, however, Meus et al. (2019) suggest that these systems might perform poorly when implemented over multiple price zones. A quantitative evaluation of such effects is still missing, even though the sliding feed-in system has already been used in the German-Danish cross-border auction (Von Blüchen et al., 2019).

\section{ANALYTICAL FRAMEWORK}

This section graphically introduces an analytical framework that illustrates how imperfect national regulatory conditions can distort the different renewable energy cooperation mechanisms. In what follows, the framework will gradually be developed. Subsection 3.1 considers optimal national policies and introduces the welfare gains of renewable cooperation via a basic sectorial trade model. Subsection 3.2 then advances towards suboptimal national policies and their implications for renewable energy trade. Subsection 3.3 shows that the SFIP can perform poorly when implemented over multiple price zones and links back to our general framework. 


\subsection{Cooperation with optimal national policies}

Figure 1 graphically presents the two-country model that will be used throughout this section. Both countries are subject to an identical renewable electricity target $T$, and the $\mathrm{x}$-axis' total length represents the combined target of these countries. For now, just consider both $M S C_{c}^{o}$-curves describing the so-called marginal support cost (see further) for country c under perfect national policies, in function of the amount of renewable electricity generated within that country. The curve of country 1 runs from left to right while the one of country 2 runs from right to left.

In earlier work, we defined the marginal support cost (MSC) as the increase in a country's total system cost to produce one additional unit of renewable electricity ${ }^{2}$ (Meus et al., 2019). The optimality condition for renewable trade directly follows from this definition: the marginal support costs in both countries should be equal ${ }^{3}$. Analogous to cross-border electricity trade, which has been arranged to harmonize electricity prices, cross-border renewable energy trade should be arranged to harmonize marginal support costs.

The marginal support cost generally comprises two main elements. The first element is the additional cost to generate one additional unit of renewable electricity (in $€ / M W h$ ). This term should be interpreted in the broad sense and encompasses all system components. One should not only consider the renewable equipment, operating, financing and installation costs; but also necessary grid connection and reinforcement costs, increased balancing requirements, any negative externalities, etc. The second element is the value of renewable electricity (also in $€ / M W h$ ) and should again be interpreted in the broad sense (Ovaere and Gillingham, 2019). Because additional renewable electricity generation replaces part of the thermal production, it will reduce the generation mix' fuel costs (i.e. the energy value of replaced generation), their accompanying local and global emissions, and possibly the need for installed thermal capacity. The marginal support cost then equals the difference of both these elements: the additional cost minus the value of a next unit of renewable electricity, considered from a system-wide perspective.

Notably, this implies that one should not solely strive to install renewable capacity in high-potential Member States. Such Member States will of course obtain higher capacity factors from their renewable equipment, which in turn can be translated into a lower investment cost per unit of generation. Renewable potential hence focusses on the cost element of the MSC, but entirely ignores the value component. It might, for instance, be cost-effective to install capacity in a Member State whose renewable generation receives higher electricity prices-indicating that higher variable cost thermal generation is being avoided — even though the mean capacity factor within that Member State is lower. To obtain an optimal distribution of renewable capacity, we should be considering the trade-off between both the system cost and -value aspects.

With this interpretation of the MSC curves, we can now start discussing the welfare gains of renewable energy trade via Figure $1^{4}$. Without any cooperation, both countries are fulfilling their targets individually (indicated by the vertical line through the center). The countries are producing at $\left(A_{1}^{o}, A_{2}^{o}\right)$ in which $A_{c}^{o}$ represents the equilibrium point for country c. A country's total additional system cost to achieve their target can be calculated as the integral of its MSC curve up to its equilibrium point. Both countries can collectively achieve a lower-cost outcome via renewable trade since the marginal support cost in country 1 is lower than in country 2 . To harmonize these,

\footnotetext{
${ }^{2}$ This subsection reinterprets the main conclusions of Meus et al. (2019). For a more comprehensive overview and proof of these claims, we refer to the original work.

${ }^{3}$ One can prove this by considering a social planner that aims to minimize the total system costs over both countries, subject to renewable electricity targets without any trade restrictions. The first-order condition of this problem is fairly standard and states that marginal system costs with respect to renewable electricity generation, i.e. the MSCs, in both countries need to be harmonized. In this illustration we rule out corner solutions and assume quadratic cost functions.

${ }^{4}$ The upward slopes in Figure 1 are mostly inspired by the scarcity of favorable locations (i.e. reduced capacity factors with increasing penetration, a cost-effect) and the self-cannibalization effect of renewable electricity (i.e. reduced electricity prices with increasing penetration, a value-effect). We are therefore considering a static framework without any cost reductions via technological advances.
} 
Figure 1: Renewable energy cooperation under national distortions: analytical overview.

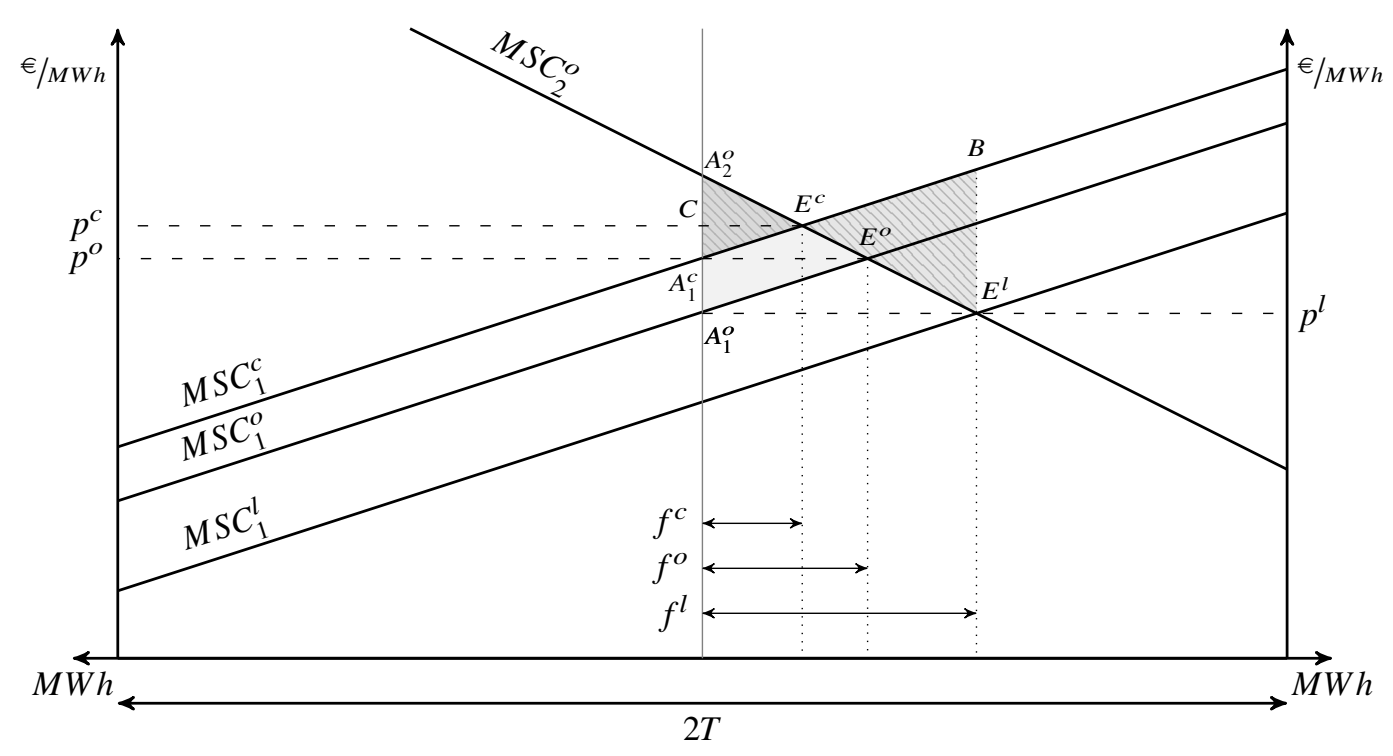

country 1 should export $f^{o}$ units of renewable electricity (in MWh) towards country 2, leading to equilibrium point $\left(E^{o}, E^{o}\right)$ and a reduction in global system $\operatorname{costs}^{5}$ of $A_{1}^{o} A_{2}^{o} E^{o}$. Following typical market conventions, exports are remunerated by the importer based on the equilibrium price $p^{o}$, i.e. country 2 financially compensates country 1 by the amount $p^{o} f^{o}$. Taking these transfers into account, one can deduce that country 1 gains $A_{1}^{o} E^{o} A_{1}^{c}$, while country 2 gains $A_{2}^{o} E^{o} A_{1}^{c}$. Renewable energy trade decreases the global cost and allows the countries to be individually better off. Note that in a fully realistic setting, the latter may not always hold as renewable trade can imply distributional shifts between countries via the electricity market (Unteutsch, 2014; Meus et al., 2019). These shifts, however, cannot be captured by our single sector model and are neglected throughout this section.

Now consider the policy mechanisms required to achieve the optimal amount of renewable cooperation. It is well-known that fixed feed-in premium systems are optimal national policy instruments when renewable energy quotas are imposed (Pahle et al., 2016). Notably, the premium level precisely corresponds to the marginal support cost in perfect markets (Meus et al., 2019). The $M C S_{c}^{o}$-curves in Figure 1 can therefore equally well be interpreted as the premium level required to achieve a certain renewable electricity target. If both countries have implemented fixed premium systems, the optimal amount of renewable energy cooperation requires harmonizing the fixed feed-in premium levels.

The key assumption here is that support (fixed premium) levels perfectly reflect the marginal support costs. Consider what this would imply in terms of national policy and general market design. The marginal support cost includes all system-wide cost and value components of a renewable electricity unit. To make sure these are reflected by the fixed premium levels, renewable investors have to be perfectly exposed to these signals as well. For national policy design this would, inter alia, imply that ${ }^{6}$ :

- Renewable investors should be charged the grid connection and reinforcement costs necessary to accommodate their generation.

${ }^{5}$ Country 1 expands its renewable generation implying an increase in total system costs equal to the area under $M S C_{1}^{o}$ from $A_{1}^{o}$ to $E^{o}$, while country 2 reduces its output leading to a decrease in system costs equal to the area under $M S C_{2}^{o}$ from $E^{o}$ to $A_{2}^{o}$.

${ }^{6}$ Inspired by Hirth et al. (2015), Hirth and Ziegenhagen (2015), Newbery et al. (2018) and Hu et al. (2018). Generally, any policy or market design that creates a wedge between the private and social value/cost of RES-E generation could be added to the list. Distortions to RES-E cooperation are therefore closely related to the concept of integration costs (Hirth et al., 2015). 
- Renewable investors should be held responsible for any increased balancing requirements, for instance via mandatory participation in properly designed balancing markets.

- Electricity prices should reflect the negative externalities of thermal generation (e.g. local and global emissions via taxes) such that renewable generation is rewarded its true social value.

- The value of renewable availability should be properly rewarded. In energy-only markets, market prices should be allowed to signal scarcity. In hybrid (energy and capacity) market systems, renewable availability should be adequately rewarded via capacity mechanisms.

The list is non-exhaustive and points out some prerequisites to ensure that marginal support costs can be captured by fixed premium levels. We certainly do not claim that every Member State should redesign its policies and markets to fulfill these conditions. Some of the items already are generally implemented and certainly allow for efficiency gains, but others might not even be desirable. Deep grid connection charges are for instance technically highly complex (Weißensteiner et al., 2011; Newbery, 2018). The point here is that some conditions in the list are typically not realized in practice (González and Lacal-Arántegui, 2016). There will thus likely be a gap between the actual marginal support cost and the fixed premium level, which has its implications for renewable cooperation mechanisms.

\subsection{Cooperation with suboptimal national policies}

Suppose that both countries still employ fixed feed-in premiums to support renewable electricity and that the premium level in country 2 still reflects its true marginal support cost. In country 1, however, there is a wedge between the marginal support cost and the fixed feed-in premium level. Consider, for instance, the example where renewable generators in country 1 are exempt from paying any grid connection and reinforcement costs, i.e. an ultra-shallow approach. The $M S C_{1}^{c}$-curve in Figure 1 represents the country's true marginal support cost, given sub-optimal national policies. The curve has shifted upward relative to the optimal case $\left(M S C_{1}^{o}\right)$ since renewable investors that are not charged any grid costs tend to select high-potential areas which often are distant, require excessive grid investment costs, and may not be optimal from the system perspective (Bjørnebye et al., 2018). The $M S C_{1}^{l}$-curve in Figure 1 presents the country's actual marginal support cost minus the additional grid costs. This curve therefore reflects the perceived marginal support cost by renewable investors and can similarly be interpreted as the fixed premium level required to attain a certain renewable electricity target. The socialization of grid integration costs essentially drives a wedge between the social and private cost of RES-E generation.

Without renewable cooperation, the equilibrium point becomes $\left(A_{1}^{c}, A_{2}^{o}\right)$. Country 1's total cost to achieve its target, i.e. the integral of the true marginal support cost curve, is larger than in the optimal case without any cooperation $\left(A_{1}^{o}, A_{2}^{o}\right)$ due to the internal misallocation that results from the exemption from grid costs.

Now suppose that both countries organize a non-discriminatory cross-border auction to support RES-E up to the point where their combined renewable electricity target is satisfied (e.g. via the URFM). Investors in country 1 do not bid the system's marginal support cost $\left(M S C_{1}^{c}\right)$, but instead their private one $\left(M S C_{1}^{l}\right)$. As can be seen from Figure 1, the FFIP level required to achieve the joint target equals $p^{l}$ which leads to equilibrium point $\left(B, E^{l}\right)$. Renewable capacity is biased towards country 1 because their TSO does not charge grid costs. One can deduce that the global gains of trade equal $A_{1}^{c} A_{2}^{o} E^{c}-E^{c} B E^{l}$. The figure thus suggests that it might actually be welfare decreasing to organize common auctions if a country has implemented sub-optimal national policies. This of course depends on the arbitrary figure layout and probably is exaggerated, but our framework does expose potentially important efficiency issues. Furthermore, distributional concerns arise as well. Similar to the analysis in Section 3.1, the portion $p^{l} f^{l}$ of country 2's subsidy stream flows towards country 1 . The net gain of country 1 therefore equals $-A_{1}^{o} A_{1}^{c} B E^{l}$ while the net gain of country 2 
Figure 2: Illustration of support levels under the fixed- and sliding feed-in premium.

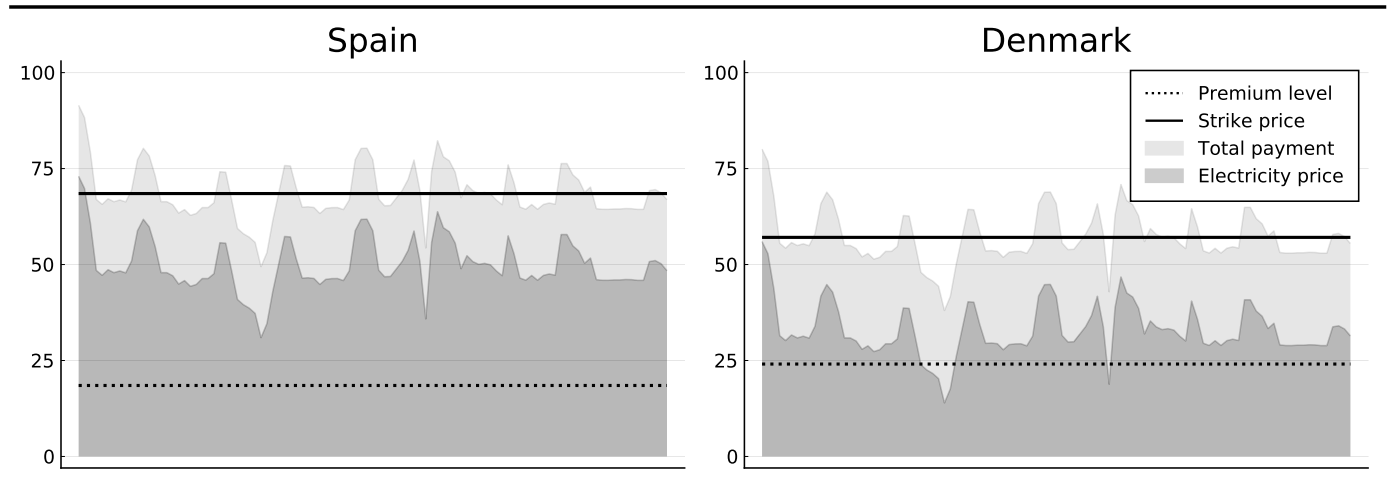

is $A_{1}^{o} A_{2}^{o} E^{c}$. Renewable transfers in this case are underpriced, which vastly benefits country 2 (the importer) at the expense of country 1 (the exporter).

Organizing renewable trade by harmonizing premium levels can thus be distortive if national regulatory conditions differ. Renewable cooperation should instead aim to harmonize the true marginal support costs, e.g. via discriminatory auctions that adjust bids based on national regulatory conditions, or via quantity-based approaches such as the URDP. In our example, such an approach could yield the equilibrium $\left(E^{c}, E^{c}\right)$, increasing total welfare by $A_{1}^{c} A_{2}^{o} E^{c}$ from which $A_{1}^{c} C E^{c}$ flows towards country 1 and $A_{2}^{o} C E^{c}$ flows towards country 2. To obtain the correct amount of renewable transfers, it is not necessary that all national policies and market designs are perfectly reflective, but it does require that one recognizes the true marginal support cost.

Figure 1 can be drawn in many different ways: the difference between $M S C_{1}^{o}$ and $M S C_{1}^{c}$ could be negligible, country 1 could have implemented policies such that $M S C_{1}^{l}$ overestimates the true marginal support cost, country 2 could have been the exporter of renewable energy, etc. The main conclusions are valid regardless of the actual case. If renewable cooperation is organized such that it ensures a convergence of the support levels, and if support levels do not reflect the marginal support costs, trade will be sub-optimal. Moreover, such an approach could lead to an underpricing (overpricing) of the transfers which will benefit the importer (exporter) at the expense of the exporter (importer).

\subsection{The sliding feed-in premium}

In Section 2, we argued that the SFIP can serve as an efficient alternative for the FFIP within a single price zone. Unfortunately, this does not necessarily hold for cross-border auctions because sliding premium systems might perform poorly when implemented over multiple price zones. Average electricity prices, and thus also the value of RES-E generation, can differ significantly across countries. Fixed premiums recognize these value differences and ensure an optimal outcome, sliding premiums do not. Consider the stylized example presented in Figure 2 which is inspired by Danish and Spanish data $^{7}$. The electricity price profile presented in the figures captures the average value observed in both countries between 2014-2016, which was roughly $33 € / M W h$ in Denmark and $50 € / M W h$ in Spain (ACER/CEER, 2017, 2018, 2019). We focus on a wind generation technology with an annualized investment cost of 150,000 $€ / M W y$. Following Staffell and Pfenninger (2016), the mean wind capacity factor in Denmark equals $30 \%$ and the one in Spain is about 25\%. For simplicity, suppose there are no system cost components besides the turbine investment cost, and no value components apart from the electricity market value.

\footnotetext{
${ }^{7}$ Von Blüchen et al. (2019) present a similar hypothetical example and state that there is no clear preference between fixed and sliding premiums in cross-border auctions. A different conclusion can be reached by interpreting electricity prices as a proxy for the avoided thermal production costs.
} 
Denmark has a clear advantage in resource potential. The Danish average wind capacity factor is higher and the country therefore needs fewer capacity investments to obtain the same amount of RES-E generation. Spanish RES-E generation contrarily captures higher electricity prices which indicates that higher variable cost thermal generation is being replaced. Denmark has lower RES-E investment costs to achieve a certain target, but Spanish RES-E generation is more valuable. This is the trade-off we introduced in Section 3.1.

To analyze the implications of a joint Danish-Spanish auction, we first calculate the national support levels required to attract investments for both premium systems. Interested readers are referred to Appendix A.1 for the details. When using the parameters defined above, the required fixed premium level in Denmark equals $24 € / M W h$, and the one in Spain is $18 € / M W h$. Similarly, the required strike price in Denmark equals $57 € / M W h$ and the one in Spain is $68 € / M W h$ (see Figure 2). Spanish RES-E capacity will thus win cross-border auctions if these are based on the fixed feed-in premium, while Danish capacity will win if based on the sliding feed-in premium (as investors would bid on the strike price).

In this simplified example, trade based on fixed feed-in premiums is optimal because these support levels precisely correspond to the marginal support cost. Promoting additional RES-E generation in Denmark would cost the system $24 € / M W h$, but promoting RES-E in Spain would only cost $18 € / M W h$. Cooperation based on the SFIP, i.e. installing turbines in Denmark instead of Spain, therefore increases the total system cost by $6 € / M W h$ relative to the autarky situation. The main issue with sliding feed-in premium systems in cross-border auctions is that these are not able to signal price- and value-difference. In fact, one can verify that the strike price equals the levelized cost of electricity, a metric that has been criticized for ignoring value-aspects.

None of this is different from the framework we presented in Subsection 3.2. The SFIP is just another case where support levels do not reflect the marginal support cost, and where trade based on imperfect support levels (the strike prices) does not guarantee the optimum. We, however, do not argue that cross-border cooperation based on sliding feed-in premiums should be ruled out a priori. The 2016 German-Danish cross-border PV auction was in fact mostly based on a sliding premium system, and the outcome probably was efficient because mean electricity prices in both countries have mostly converged ${ }^{8}$. The benefits of sliding premiums can thus still be leveraged in cross-border auctions if mean electricity prices are about equal in both countries, and if the size of the auction is sufficiently small to not affect electricity prices. On the European level, however, this convergence condition does not yet hold. Mean Iberian electricity prices are for instance about $10-15 € / M W h$ above Scandinavian ones (ACER/CEER, 2019). An EU-wide auction based on sliding premiums will likely lead to sub-optimal outcomes.

\section{MODEL}

To quantify the importance of these distortions, we now develop a partial equilibrium model that can generally be interpreted as a Stackelberg game. The upper level comprises the policy makers of all countries, which are assumed to be fully collaborative. Put differently, policy makers are modelled as a single entity aiming to maximize total welfare regardless of the distributional consequences. The policy makers are subject to a renewable quota constraint and steer the lower level equilibrium by setting the support levels. The lower level comprises conventional generators, renewable generators, storage operators, interconnection operators and market operators. The conventional power plant portfolio is assumed to be fixed while RES investments are possible. All lower-level agents aim to maximize profit and are assumed to behave perfectly competitive. We assume that all agents have perfect information and model a zonal pricing system where the electricity price within a Member State is uniform. We furthermore include the possibility of (i) different grid connection cost regimes and (ii) different premium implementations. Although these problem formulations are generally

${ }^{8}$ For more information on German-Danish cross-border pilot auction, we refer to Von Blüchen et al. (2019) 
computationally demanding to solve, our specific set-up allows for an iterative algorithm. This solution strategy is leveraged to solve for rather large instances and is presented in Appendix A.2.

\subsection{Thermal generator}

We are considering a fixed conventional power plant portfolio where generators can only make production decisions, subject to a capacity constraint. Additional technical power plant limitations are neglected. The conventional generators set their production to maximize profit:

$$
\begin{aligned}
\max _{y_{c, s, t}} & \sum_{c, s, t}\left(p_{c, t}^{e}-V C_{s}\right) y_{c, s, t} \\
\text { s.t. } & 0 \leq y_{c, s, t} \leq \bar{Y}_{c, s, t} \quad\left(\lambda_{c, s, t}^{c}\right) \quad \forall c, s, t
\end{aligned}
$$

Their decision variable $y_{c, s, t}$ represents the production in country $c$ from conventional technology $s$ during time-step $t$. $p_{c, t}^{e}$ symbolizes the electricity price in country $c$ during time-step $t$ and is considered to be a parameter in this optimization problem (i.e. price-taking behavior). Parameters $V C_{s}$ and $\bar{Y}_{c, s, t}$ respectively represent the variable production cost of conventional technology $s$, and the maximum amount of that technology's capacity in country $c$. This maximum capacity limit can vary over time, which allows to exogenously impose power plant outages. The solution to this problem is fairly standard: conventional generators follow the merit-order curve and only generate if the electricity price covers their variable cost.

\subsection{Renewable generator}

Renewable investors make investment and generation decisions to maximize their profit whilst taking the support levels and electricity prices as given. Our case study focuses on onshore wind energy where investment decisions are restricted to a set of sites $i \in \mathcal{I}$. To reflect the scarcity of favorable locations, we impose an upper limit on the amount of turbines that can be installed per site $\left(\bar{N}_{i}\right)$. Furthermore, the maximum power output of a turbine $\left(P_{i, t}\right)$ is restricted by wind conditions which vary across locations and over time. Mathematically, the problem can be formulated as:

$$
\begin{aligned}
\max _{x_{c, t}, n_{i}} & \sum_{c, t}\left(p_{c, t}^{e}+f i p_{c, t}\right) x_{c, t}-\sum_{i}\left(C^{i n v}+\theta_{c} I_{c, i} C_{i}^{g r i d}\right) n_{i} \\
\text { s.t. } & 0 \leq x_{c, t} \leq \sum_{i} P_{i, t} I_{c, i} n_{i} \quad\left(\lambda_{c, t}^{r}\right) \quad \forall c, t \\
& 0 \leq n_{i} \leq \bar{N}_{i} \quad\left(\delta_{i}\right) \quad \forall i
\end{aligned}
$$

Where decision variables $x_{c, t}$ and $n_{i}$ respectively represent the aggregate wind generation in country $c$ during time-step $t$, and the amount of installed turbines at site $i$. The remuneration term in the objective function scales with electricity prices $\left(p_{c, t}^{e}\right)$ and the premium level $\left(f i p_{c, t}\right)$. The premium depends on the time as this is a rather flexible approach which allows to model both the FFIP and SFIP. This time-dependent premium level will be connected to the actual support levels in Subsection 4.6. Parameter $C^{i n v}$ symbolizes the equipment and installation cost for a turbine, which is assumed to be constant over locations. Parameter $C_{i}^{\text {grid }}$ represents the grid connection costs per turbine ${ }^{9}$ and varies per site. The grid cost allocation cases are controlled by the binary parameter $\theta_{c}$ which equals 1

\footnotetext{
${ }^{9}$ This is an approximation to avoid binary variables. More accurate would be to charge the full grid connection costs if a site is being used, regardless of the amount of turbines installed at that site. Nonetheless, the model outcomes indicate that it is preferable to fully utilize a site before moving to the next one. The discrete cost character is thus retained and the approximation should be able to adequately capture the implications of grid connection costs.
} 
if grid connection costs have to be financed by renewable investors and 0 if these costs are socialized via the TSO (effectively removing these costs form the renewable generator's problem). The binary parameter $I_{c, i}$ links renewable sites to countries, equals 1 if country $c$ comprises site $i$ and 0 elsewise. Constraint 4 restricts a country's aggregate wind generation to correspond with wind conditions, and Constraint 5 imposes the land scarcity condition.

\subsection{Storage operator}

The storage operator obtains revenue from temporal arbitrage in the electricity market. As for the conventional portfolio, we assume that storage capacity is fixed and that additional investments are not possible.

$$
\begin{array}{rlll}
\max _{s_{c, t}^{d c}, s_{c, t}^{c}, e_{c, t}} & \sum_{c, t} p_{c, t}^{e}\left(s_{c, t}^{d c}-s_{c, t}^{s}\right) & \\
\text { s.t. } & 0 \leq s_{c, t}^{d c} \leq \bar{S}_{c, t}^{d c} \quad\left(\beta_{c, t}^{d c}\right) & \forall c, t \\
& 0 \leq s_{c, t}^{c} \leq \bar{S}_{c, t}^{c} \quad\left(\beta_{c, t}^{c}\right) \quad \forall c, t \\
& 0 \leq e_{c, t} \leq \bar{E}_{c, t} \quad\left(\beta_{c, t}^{e}\right) \quad \forall c, t \\
& e_{c, t}=e_{c, t-1}+\eta s_{c, t}^{c}-\frac{s_{c, t}^{d c}}{\eta} \quad\left(\gamma_{c, t}\right) & \forall c, t
\end{array}
$$

The storage owner in country $c$ sets its charging power $\left(s_{c, t}^{c}\right)$, discharging power $\left(s_{c, t}^{d c}\right)$ and the reservoir's energy content $\left(e_{c, t}\right)$ for every time-step $t$ to maximize profit. Eqs. 7 - 9 respectively impose the technical limits on discharging power, charging power and the state-of-charge. Constraint 10 ensures consistency in the temporal evolution of the system's energy content, which is affected by the charging and discharging efficiency $(\eta)$. We additionally impose a cyclic boundary condition which ensures that the energy content during the first and final period is equal.

\subsection{Interconnection operator}

The interconnection operator performs spatial arbitrage across pricing zones (Member States). We model flow limits via constant net transfer capacities (NTCs) and again assume that no capacity additions are possible.

$$
\begin{array}{cll}
\max _{f_{l, t}} & \sum_{c, t}\left[p_{c, t}^{e} \sum_{l} A_{c, l} f_{l, t}\right] & \\
\text { s.t. } & \bar{F}_{l}^{p}-f_{l, t} \geq 0 \quad\left(\epsilon_{l, t}^{p}\right) & \forall l, t \\
& \bar{F}_{l}^{n}+f_{l, t} \geq 0 \quad\left(\epsilon_{l, t}^{n}\right) & \forall l, t
\end{array}
$$

The decision variable $f_{l, t}$ represents the power flow over line $l$ during time-step $t$. Constraints $12-13$ restrict the power flow in both the positive and negative direction to the NTC values $\left(\bar{F}_{l}^{p}, \bar{F}_{l}^{n}\right)$. The matrix $A$ defines the cross-border transmission topology. Entry $A_{c, l}$ equals 1 if a positive power flow on line $l$ implies an injection into country $c$, and equals -1 if this implies a flow exiting country $c$. Line $l$ is not connected to country $c$ if $A_{c, l}$ equals zero. The factor $\sum_{l} A_{c, l} f_{l, t}$ in the objective function therefore represents the net power inflow for country $c$ during time-step $t$. 


\subsection{Market operator}

The market operator sets the electricity price $\left(p_{c, t}^{e}\right)$ to ensure that demand matches supply. Intracountry transmission constraints are assumed to be non-binding and we furthermore consider an inelastic electricity demand $\left(D_{c, t}\right)^{10}$.

$$
\sum_{s} y_{c, s, t}+x_{c, t}+s_{c, t}^{d c}-s_{c, t}^{c}+\sum_{l} A_{c, l} f_{l, t}=D_{c, t} \quad\left(p_{c, t}^{e}\right) \quad \forall c, t
$$

\subsection{Policy maker}

The policy makers jointly form the upper-level agent which is subject to the lower level equilibrium defined by Eqs. $1-14$. Such an MPEC structure can generally be solved by formulating the first-order (KKT) conditions of the lower-level agents-which are presented in Appendix A.2 - and inserting these as constraints in the upper-level agent's problem. Depending on the renewable energy cooperation variant, the MPEC structure may simplify into an MCP formulation. One can observe that the policy makers are only able to influence the lower-level equilibrium via the premium levels $\left(f_{i p}, t\right)$. The problem formulation of the policy maker depends on (i) the national support instruments and (ii) the renewable cooperation variant.

\subsubsection{National support instruments}

Recall that we are including two support instruments: the fixed- and sliding feed-in premium. The FFIP can be modelled via:

$$
f i p_{c, t}=s l_{c} \quad \forall c, t
$$

The time-dependent premium in Eq. 3 is defined by Eq. 15, which states that the premium received on top of the electricity price remains constant over time and equals the support level $\left(s l_{c}\right)$ set by the policy maker.

The SFIP resembles the FFIP, but the premium $\left(s f i p_{c, b}\right)$ paid on top of the electricity price varies per block $(b \in \mathcal{B})$ and is calculated as the difference between the strike price (support level) and the average electricity price during that block. Furthermore, if the average electricity price exceeds the strike price, the premium is set to zero and cannot be negative. In this paper we use a block size of one month for each country. Mathematically, the strike price (i.e. the support level) can be linked to the time-dependent premium via:

$$
\begin{gathered}
\operatorname{fip}_{c, t}=\sum_{b} B_{b, t} \text { sip }_{c, b} \quad \forall c, t \\
s f i p_{c, b}-s l_{c}+\frac{1}{N_{b}} \sum_{t} B_{b, t} p_{c, t}^{e} \geq 0 \perp s f i p_{c, b} \geq 0 \quad \forall c, b
\end{gathered}
$$

In which $B_{b, t}$ is a binary parameter that equals 1 if block $b$ comprises time-step $t$, and 0 elsewise. $N_{b}$ is a parameter representing the block size, i.e. the amount of time-steps within block $b$. Eq. 16a links the time-dependent premium level (Eq. 3) to the sliding premium level during the corresponding block $b$. The premium level remains constant within a time-block, but can differ across these blocks.

\footnotetext{
${ }^{10}$ The original model includes the possibility for load curtailment to avoid infeasible or unreasonable solutions. We refrain from presenting this extension because none of the model outcomes resort to curtailment.
} 
Eq. 16b sets the sliding premium equal to the difference between the support level (i.e. strike price) and the average electricity price if this is positive, and equal to zero elsewise.

\subsubsection{Renewable energy cooperation variants}

We include three renewable cooperation variants: no cooperation, harmonizing support levels (e.g. via a non-discriminatory joint auction) and harmonizing marginal support costs (e.g. via a discriminatory auction or via the URDP, Section 3.2). Starting with the no cooperation case, each Member State achieves its individual target by appropriately setting their national support level:

$$
\begin{aligned}
& \sum_{t} x_{c, t}=\text { Target }_{c} \quad \forall c \\
& \text { Market equilibrium: (32) - (48) } \\
& \text { Support instrument: } \begin{cases}(15) & \text { if FFIP } \\
(16) & \text { if SFIP }\end{cases}
\end{aligned}
$$

Eq. 17 states that the total amount of yearly renewable electricity generation in country $c$ should exactly equal its national target. Eq. 18 imposes the first-order conditions from the market equilibrium and Eq. 19 selects the proper support instrument formulation. Note that this latter is considered to be a case and thus determined exogenously. The original MPEC structure has been simplified into an MCP formulation where the policy makers act as lower-level clearing agents. As in Meus et al. (2021), this problem can be formulated as an MPEC where the policy makers minimize the total cost subject to a constraint stating that the renewable generation should be higher than or equal to the target (i.e. $\sum_{t} x_{c, t} \geq$ Target $_{c}$ ). The equivalence of both formulations holds because (i) positive subsidy levels imply that the optimal solution satisfies the quota constraints with equality ${ }^{11}$ and because (ii) it can be shown that the problem has an unique solution.

The non-discriminatory cross-border auction can be reformulated into an MCP following a similar line of reasoning:

$$
\begin{aligned}
\sum_{c, t} x_{c, t} & =\sum_{c} \text { Target }_{c} \\
s l_{c} & =\overline{s l} \quad \forall c
\end{aligned}
$$

Market equilibrium: (32) - (48)

Support instrument: $\begin{cases}(15) & \text { if FFIP } \\ (16) & \text { if SFIP }\end{cases}$

The national quota constraints are relaxed into one global target (Eq. 20) and there is an additional constraint stating that the support levels need to be harmonized over all countries (Eq. 21). Harmonized support levels are usually outcomes of non-discriminatory cross-border auctions, but it is simpler and equivalent to explicitly impose this condition in the mathematical formulation.

The third cooperation case (harmonizing MSC) guarantees an optimal amount of renewable cooperation, even though national policies may not be perfect. Policy makers recognize that the convergence of support levels might not be appropriate and can set diverging support levels across countries to minimize the total system $\operatorname{cost}^{12}$ :

\footnotetext{
${ }^{11}$ Given positive subsidy levels, increasing the renewable electricity penetration is welfare decreasing. Furthermore, the model outcomes always include positive subsidy levels.

${ }^{12}$ Maximizing welfare coincides with minimizing cost because demand for both electricity and renewable electricity (i.e.
} 


$$
\begin{array}{ll}
\min & \sum_{i}\left(C^{i n v}+C_{i}^{g r i d}\right) n_{i}+\sum_{c, s, t} V C_{s} y_{c, s, t} \\
\text { s.t. } & \sum_{c, t} x_{c, t}=\sum_{c} \text { Target }_{c} \\
& \text { Market equilibrium: } \quad(32)-(48) \\
\text { Support instrument: } & \begin{cases}(15) & \text { if FFIP } \\
(16) & \text { if SFIP }\end{cases}
\end{array}
$$

There is one global target for renewable electricity (Eq. 25), and the support levels in the respective countries no longer need to be harmonized (i.e. Eq. 21 is dropped). The total system cost comprises renewable investment costs, grid connection costs and thermal production costs. Grid connection costs are financed either by renewable investors or the TSO, but always contribute to the total cost regardless of the allocation. Note that the investment costs of the present power plant portfolio are assumed sunk.

\subsection{The additional system cost}

We conclude this section by introducing the main metric used to assess the model outcomes: the additional system cost. Formally:

$$
\begin{aligned}
& T S C^{k}=\sum_{i}\left(C^{i n v}+C_{i}^{g r i d}\right) n_{i}^{k}+\sum_{c, s, t} V C_{s} y_{c, s, t}^{k} \\
& A S C^{k}=T S C^{k}-T S C^{0}
\end{aligned}
$$

The superscript $k$ refers to the scenario. The respective scenarios will be defined in Section 5 and vary in terms of connection cost allocation, premium system and cooperation mechanism. Eq. 28 defines the total system cost for scenario $k$ and comprises the same elements as Eq. 24. In our context, it is more reasonable to consider the additional system cost defined by Eq. 29. Indeed, we are mostly interested in the additional policy cost to achieve a predefined renewable electricity target and not as much in the total cost to satisfy both the renewable target and the electricity demand. We therefore subtract the total system cost (Eq. 28) of a reference scenario from Eq. 28. This reference scenario corresponds to the lower-level market equilibrium model without any policy intervention, i.e. the solution to Eqs. 32 - 48 without renewable subsidies.

\section{CASE STUDY}

We apply the model to a case study that examines cooperation in onshore wind energy among France, Germany, the Netherlands and Belgium. These four countries were selected because they encompass quite diverse thermal production portfolios and exhibit various technical potentials for wind generation. In what follows, Subsection 5.1 introduces the different scenarios which allow to cross-wise compare the implications of different national policies on the three implementations of renewable cooperation. Subsection 5.2 discusses the data setup. 
Table 1: Overview of scenarios considered in the case study (MSC = marginal support cost; SL = support level).

\begin{tabular}{|c|c|c|c|c|c|}
\hline \multicolumn{3}{|c|}{ National policies } & \multicolumn{3}{|c|}{ Cooperation variant } \\
\hline Case & Support instrument & Grid cost allocation (BE, FR) & Autarky & SL & MSC \\
\hline 1 & FFIP & RES-E & $\mathrm{x}$ & $\mathrm{x}$ & $\mathrm{x}$ \\
\hline 2 & FFIP & TSO & $\mathrm{x}$ & $\mathrm{x}$ & $\mathrm{x}$ \\
\hline 3 & SFIP & RES-E & $\mathrm{x}$ & $\mathrm{x}$ & $\mathrm{x}$ \\
\hline 4 & SFIP & TSO & $\mathrm{x}$ & $\mathrm{x}$ & $\mathrm{x}$ \\
\hline
\end{tabular}

\subsection{Scenario overview}

Table 1 presents an overview of the 12 combinations of national policies and cooperation mechanisms that are considered in the case study. Concerning national support instruments, a Member State could implement the FFIP or the SFIP. Since the case study includes four countries, and because each country can implement one out of two support instruments, it is possible to conceive $16\left(=2^{4}\right)$ combinations within this category. For conciseness, we only consider the cases where all four Member States employ fixed feed-in premiums, and where all Member States implement sliding feed-in premiums ${ }^{13}$.

Grid connection costs can be allocated to renewable investors (shallow connection charging) or socialized via the transmission system operator (ultra-shallow connection charging). Grid reinforcement costs are omitted because of computational difficulties. As such, we assume that the transmission network is able to accommodate the additional wind generation. There again are 16 possible combinations from which we select two. German and Dutch renewable investors are always required to finance the grid connection costs. Belgium and France jointly allocate the connection costs to renewable investors (RES-E) or socialize these via the transmission system operator (TSO).

The four resulting national policy combinations are cross-wise combined with the three cooperation mechanisms: no cooperation, harmonizing support levels and harmonizing the MSC. Note that the first national policy case concerns perfectly reflective national policies. The support level therefore equals the marginal support cost and the grey-marked entries in Table 1 give rise to the same equilibrium. The other three cases induce a wedge between the support level and the marginal support cost.

\subsection{Data}

This section briefly introduces the data setup. Actual parameter values (or summary statistics thereof) are presented in Appendix A.3. To limit the computational effort, we only include the year 2018 using an hourly resolution. The case study comprises five thermal production types: nuclear, lignite, coal, CCGT and OCGT. The variable cost for each technology is calculated as the sum of fuel costs, carbon emission costs and variable operation and maintenance (VOM) costs. All techno-economic parameters are compiled from IEA and NEA (2015); Van den Bergh and Delarue (2015); Hirth (2017); Ward et al. (2019). Existing thermal capacities are taken from Platts (2013); Open Power System Data (2019); ENTSO-E (2020) and are adjusted to account for power-plant outages as reported by ENTSO-E (2020). Note that power plant outages are therefore exogenously imposed and not optimized.

Power and energy limits of pumped hydro-storage reservoirs are aggregated per country and are obtained from Platts (2013); Geth et al. (2015). The interconnectors' net transfer capacities are taken from ENTSO-E (2020). We account for currently installed renewable capacity by subtracting

the quota) is inelastic.

${ }^{13}$ The other combinations do not lead to additional insights. 
Figure 3: Sorted levelized cost of electricity (LCOE) of onshore wind power to achieve an additional 10 $\%$ onshore wind penetration. Solid and dashed lines represent the total LCOE (investment and grid connection costs), dotted lines exclude the grid connection costs.

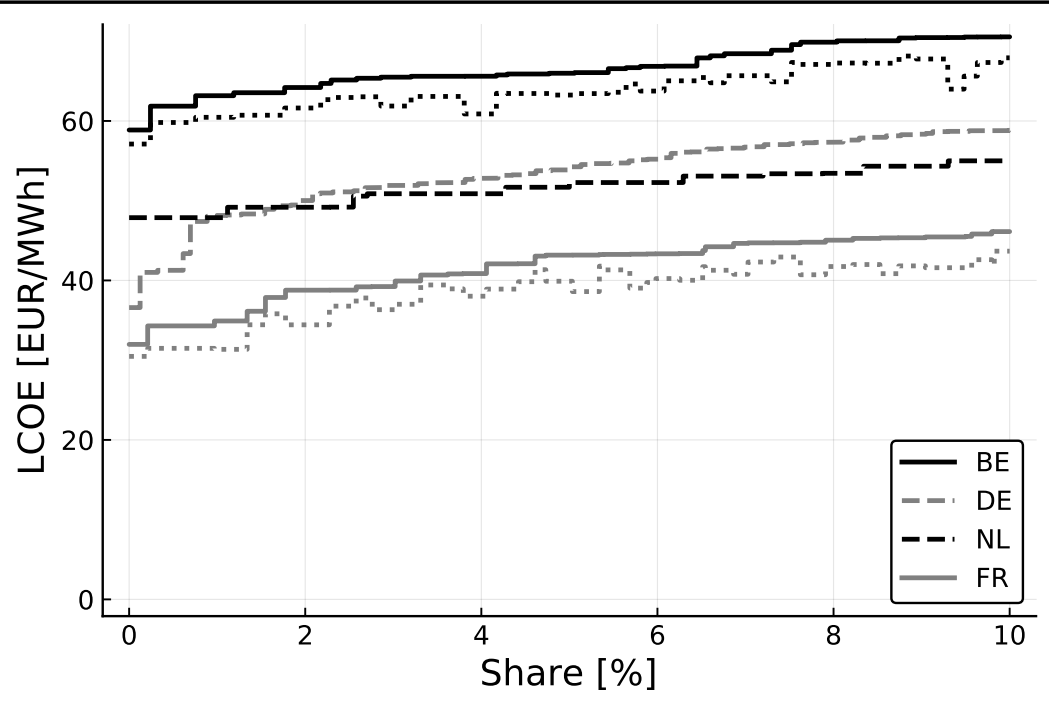

their generation from gross electricity demand (both taken from Open Power System Data (2018)). This residual demand profile is additionally adjusted to compensate for electricity imports and exports across the geographical boundary of our system (taken from ENTSO-E (2020)). Concerning the national targets, we take on a short-term perspective and assume that the additional wind energy generation should cover $5 \%$ of electricity demand. This yields a global target (over the four countries) which can then be allocated to the individual countries proportional to their planned onshore capacity expansions (European Commission, 2020).

We consider 5,000 potential wind turbine sites which are derived from the data of Ryberg et al. (2019). Each site is characterized by (i) a power generation profile over time and (ii) a maximum amount of turbines that can be installed at that site. Further details, along with turbine and grid connection cost information, can be found in Appendix A.3. Figure 3 summarizes the outcome of the wind energy parameters and yields some insights into the relative wind potentials. The figure presents the levelized cost of electricity (LCOE) for wind turbines, sorted from low to high, until the total amount of additional wind energy satisfies $10 \%$ of electricity demand ${ }^{14}$. The solid lines include all costs $\left(C^{i n v}+C_{i}^{\text {grid }}\right)$ and slope upward because of the scarcity of favorable locations, i.e. a location is completely packed at the vertical jumps. One can note that France is relatively well-endowed with onshore wind potential whilst Belgium is not as much. The dotted lines follow the same order of locations, but exclude the grid connection costs. Note that we only present these values for Belgium and France because these countries may allocate grid connection costs to the TSO. One can see that the grid connection costs constitute a relatively small share of the LCOE, averaging roughly $3 € / \mathrm{MWh}$.

\section{RESULTS}

This section discusses the global additional system costs (Eq. 29). Additional performance metrics are introduced when appropriate. For conciseness, we only discuss country-level variables for Germany and France. The ones for Belgium and the Netherlands follow a similar line of thought and do not add

$$
{ }^{14} \operatorname{LCOE} E_{i}=\frac{C^{i n v}+C_{i}^{g r i d}}{\sum_{t} P_{i, t}}
$$


Table 2: Additional system cost in $M € / y$. Percentage values relative to the optimum (Case 1, MSC) presented between brackets.

\begin{tabular}{clll} 
& \multicolumn{3}{c}{ Cooperation variant } \\
\cline { 2 - 4 } Case & Autarky & SL & MSC \\
\hline 1 & $302(37.5)$ & $220(0.0)$ & $220(0.0)$ \\
2 & $307(39.5)$ & $235(6.8)$ & $220(0.2)$ \\
3 & $302(37.5)$ & $378(72.1)$ & $220(0.2)$ \\
4 & $307(39.5)$ & $473(115.1)$ & $221(0.7)$ \\
\hline
\end{tabular}

Table 3: Yearly amount of wind energy in France and Germany. Values in $T W h / y$.

\begin{tabular}{cccccccc} 
& \multicolumn{3}{c}{ France } & & \multicolumn{3}{c}{ Germany } \\
\cline { 2 - 4 } \cline { 6 - 8 } Case & Autarky & SL & MSC & & Autarky & SL & MSC \\
\hline 1 & 18.9 & 26.7 & 26.7 & & 36.1 & 22.9 & 22.9 \\
2 & 18.9 & 32.1 & 26.4 & & 36.1 & 19.4 & 23.2 \\
3 & 18.9 & 50.0 & 27.0 & & 36.1 & 7.8 & 22.5 \\
4 & 18.9 & 55.6 & 26.7 & & 36.1 & 3.5 & 22.9 \\
\hline
\end{tabular}

additional insights ${ }^{15}$. Supplementary model results concern country-level distributional implications and are discussed in Appendix A.4.

Table 2 presents the yearly additional system cost and also presents these values relative to the optimum between brackets ${ }^{16}$. The national policy cases are defined as in Table 1. Unconstrained renewable cooperation with perfect national policies (case 1) always guarantees the optimal outcome ${ }^{17}$. We start by discussing the autarky situation, then move to the optimal cooperation (i.e. harmonizing marginal support costs) and end with the cross-border auctions (i.e. harmonizing support levels).

One can notice that implementing sliding premiums instead of fixed premiums does not have any impact on the system cost when the countries are not cooperating ${ }^{18}$. Improperly allocating grid connection costs, in contrast, slightly increases the additional system cost from $302 M € / y$ to $307 M € / y$. This can be explained by the non-monotonicity of the dotted curves in Figure 3 . Renewable investors ignore connection costs and typically opt for those locations with the highest power output. Some of these locations require excessive grid connection costs, which makes them less desirable from a system perspective. The inefficiency is nonetheless marginally small, at least when there is no renewable cooperation.

Significant cost savings are possible when moving to an optimal amount of renewable cooperation, as indicated by the MSC-column in Table 2. The table shows that not engaging in renewable cooperation incurs an additional policy cost of $38 \%-40 \%$. The results also demonstrate that a perfectly organized renewable cooperation mechanism is extremely robust with respect to national policy distortions. Indeed, the MSC-cost outcomes in Table 2 are approximately identical regardless of the national case. Table 3 provides the underlying reason by presenting the yearly amount of generated wind electricity in France and Germany. The autarky column in Table 3 simply presents the national targets. By comparing this to the MSC-column in the table, one can deduce that France typically exports renewable energy whilst Germany typically imports. This is predominantly driven by renewable potential reasons, see Figure 3. More interesting, renewable cooperation is able to compensate for inefficient national policies. Compare for instance the yearly wind energy

\footnotetext{
${ }^{15}$ As will be discussed below, France generally exports renewable energy whilst Germany typically imports. Likewise, Belgium acts as an importer and the Netherlands as an exporter. The implications of renewable trade for Belgium therefore mostly correspond to those of Germany, while those of the Netherlands are typically reflected by those of France.

${ }^{16}$ Recall that we simulate one single year and use annualized investment values. All cost outcomes should therefore be interpreted as yearly recurrent costs.

${ }^{17}$ It can be shown that this case corresponds to the central planner's solution (Meus et al., 2019)

${ }^{18}$ This is more thoroughly shown in Meus et al. (2021).
} 
Table 4: Support levels in France and Germany, average premium levels between brackets. All values presented in $€ / M W h$.

\begin{tabular}{cccccccc} 
& \multicolumn{3}{c}{ France } & & \multicolumn{3}{c}{ Germany } \\
\cline { 2 - 4 } \cline { 7 - 8 } Case & Autarky & SL & MSC & & Autarky & SL & MSC \\
\hline 1 & $3.7(3.7)$ & $8.6(8.6)$ & $8.6(8.6)$ & & $12.5(12.5)$ & $8.6(8.6)$ & $8.6(8.6)$ \\
2 & $1.6(1.6)$ & $7.6(7.6)$ & $5.5(5.5)$ & & $12.5(12.5)$ & $7.6(7.6)$ & $8.7(8.7)$ \\
3 & $39.7(4.3)$ & $49.2(18.5)$ & $44.7(9.4)$ & & $58.0(12.3)$ & $49.2(2.8)$ & $54.4(8.4)$ \\
4 & $31.8(1.9)$ & $46.7(16.9)$ & $40.5(6.1)$ & & $58.0(12.3)$ & $46.7(0.4)$ & $54.4(8.4)$ \\
\hline
\end{tabular}

generation of cases 1 and 2 under perfect cooperation in Table 3. France allocates its grid connection costs inefficiently in case 2, and the optimal cooperation mechanism will therefore slightly adjust capacity from France towards Germany. As in Subsection 3.2, the true marginal support cost within a country shifts upwards if that country implements sub-optimal policies.

Now consider what happens if the support levels must be harmonized, i.e. the outcome of a cross-border auction. Given perfect national policies, this cooperation variant is optimal because harmonizing fixed premium levels also ensures harmonizing marginal support costs. Significant efficiency losses can, however, arise with imperfect national policies (cases 2-4). Table 2 indicates that the policy cost is $7 \%$ higher than necessary for case 2 . Recall that in this case, RES-E generation is subsidized via fixed feed-in premiums, but French renewable investors are exempt from grid connection costs whilst German investors are not. Wind capacity consequently is biased towards France if support levels are harmonized, see Table 3. What actually should happen is illustrated in Table 4, which presents the required support levels in France and Germany. Cooperation based on harmonizing support levels would result in a uniform fixed premium level of $7.6 € / M W h$ to satisfy the global renewable quota. It would, however, be better to not harmonize the support schemes and to grant German investors a higher support level $(8.7 € / M W h)$ than French ones $(5.5 € / M W h)$. By doing so, policy makers offset the national policy differences. Note also that cooperation based on support levels exacerbates the inefficiency of misallocating grid connection costs. Indeed, the $7 \%$ additional policy cost arises from a fairly small cost component (Figure 3). The effects will likely be worse when considering more significant distortions, e.g. deep vs. shallow connection charging.

Cross-border auctions based on the sliding feed-in premium perform extremely poorly in our case study, even worse than no renewable cooperation at all (Table 2). As mentioned in Subsection 3.3, harmonizing strike-prices biases renewable capacity towards countries with the highest renewable potential. In our case study, France thereby significantly expands its wind power portfolio. The problem is that France's renewable electricity generation is amongst the least valuable, especially at higher penetrations. France already has slightly lower electricity prices in the reference scenario, i.e. without renewable support, because the country mostly relies on nuclear generation. Injecting additional RES-E generation into their power system will congest the cross-border transmission network, will further decrease the average French electricity prices and will gradually lower the value of their wind energy. As mentioned in Subsection 3.3, the cross-border auction among Denmark and Germany was efficient because average electricity prices in both countries were about equal, and because the auctioned capacity was fairly limited. If both countries would subsidize more capacity by continuing to cooperate via the sliding feed-in premium, similar effects will likely occur. Table 4 again presents what should ideally happen in terms of support levels. For case 3, the strike prices among countries should be adjusted to include the varying electricity prices (and thus the diverging value of RES-E generation). For case 4, the strike prices should be adjusted to include (i) the varying electricity prices and (ii) the misallocation of the grid connection costs. Note also that the inefficiency of the cross-border auction is quite a bit higher for case 4 . Because both national distortions will bias renewable capacity towards France, the differences between the marginal support costs will increase, and the marginal benefit of cooperation will be even more negative (see Figure 1). Aggregated national distortions can be mutually reinforcing. 


\section{CONCLUSION AND POLICY IMPLICATIONS}

Renewable energy cooperation mechanisms can significantly reduce the policy costs to fulfill national renewable energy targets. In our case study, the additional policy cost of not cooperating is about $40 \%$ higher than necessary. Furthermore, adequately designed cooperation mechanisms always allow for efficiency gains, even if the participating countries do not implement perfect policies.

Cooperation mechanisms must be designed to allow for an harmonization of marginal support costs. This optimality condition is not necessarily fulfilled when harmonizing support levels, e.g. via non-discriminatory cross border auctions. Imperfect national policies drive a wedge between the private and social value or cost of RES-E generation. This wedge, in turn, creates a gap between the support levels and the marginal support cost. We analyzed the effects of (i) differently allocating grid connection costs and (ii) using a sliding instead of a fixed feed-in premium system to promote RES-E generation. The results indicate that these distortions are significant and can mutually reinforce each other. In fact, cross-border auctions based on the sliding feed-in premium can perform worse than no renewable cooperation at all.

Supplementary results in the Appendix confirm the existence of country-level distributional concerns. Renewable energy cooperation affects electricity prices and changes the terms of trade in the electricity market. Member States may consequently be worse off because they receive less for their electricity exports or pay more for their imports. We additionally reveal that renewable transfers may be mispriced because of imperfect national policies. Underpricing these transfers will benefit the importer at the expense of the exporter and vice versa. Both effects are significant and can thus act as a strong barrier to engage in renewable energy cooperation mechanisms.

The main policy implication is that one needs to pay attention when organizing cross-border auctions for renewable electricity. These should ideally not be based on sliding feed-in premiums since renewable capacity will then be biased towards high potential Member States, even if their electricity market value is low. In addition, granting uniform subsidies to renewable installations can be sub-optimal even if the system is based on the fixed feed-in premium. Various non-harmonized national policies will decrease the efficiency of cross-border auctions if these are non-discriminatory. One should opt for an auction system that ensures the convergence of marginal support costs, instead of one that ensures the convergence of support levels.

Designing such auction systems is of considerable interest for future research, especially given the EU's intentions to start organizing cross-border auctions. Additionally, our case study is quite restrictive with respect to (i) the amount of Member States and (ii) the national policy distortions. Future research can conceive better approaches to calculate the gains of trade for practical case studies whilst taking into account the market dynamics. Finally, more research is required on how to mitigate the distributional shifts and on when these actually can occur. Future work might explore more innovative pricing schemes that better align a Member State's individual benefit with the global gains.

\section{ACKNOWLEDGMENTS}

This paper has received support from the Belgian Energy Transition Fund, project Neptune.

\section{APPENDIX}

\section{A.1 Stylized support level calculation}

This section calculates the break-even support levels used to illustrate the effects of implementing cross-border sliding feed-in premiums (Section 3.3). As in Meus et al. (2021), these support levels can be calculated by formulating an expression for the renewable investor's profit, setting this expression equal to zero (i.e. the break-even condition), and extracting the subsidy level. For the sliding feed-in 
premium, we suppose that the reference price is recalculated based on the long-term average (e.g. yearly). This implies that there is one single time-block capturing all hours, and also that the sliding and fixed premiums would be equivalent (Huntington et al., 2017). It is the most straightforward implementation in our context, but the same conclusions hold if there are monthly or hourly blocks. The break-even conditions for both support instruments can be formulated as:

$$
\begin{aligned}
N \cdot C F_{c}\left(p_{c}^{e}+f f i p_{c}\right)-C^{i n v} & =0 \\
N \cdot C F_{c}\left(p_{c}^{e}+s f i p_{c}\right)-C^{i n v} & =0, \quad s f i p_{c}=S P-p_{c}^{e}
\end{aligned}
$$

Where $f f i p_{c}$ and $S P$ represent the required support level to attract capacity in country c under the fixed and sliding feed-in premium system, respectively. $N$ represents the amount of hours per year $(8760 h / y), C F_{c}$ the average capacity factor in country c, $p_{c}^{e}$ the mean electricity price in that country, and $C^{i n v}$ the annualized investment cost. $s$ fip $p_{c}$ represents the sliding feed-in premium which is endogenously determined as the difference between the strike price and the mean electricity price. It is trivial to confirm that $f f i p_{c}=s f i p_{c}$, which only holds because we consider one single time-block. Note also that we make the implicit assumption that the value factor of renewable electricity generation in both countries equals 1, i.e. RES-E production on average receives the mean electricity price (Hirth, 2013). Again, this is to make the example less involved and does not alter the conclusions.

\section{A.2 Solution strategy}

The model introduced in Section 4 can be reformulated as a single-objective optimization problem and solved iteratively to obtain the equilibrium outcome. Specifically, all KKT-conditions of the lower-level problem (Eqs. 1 - 14) are presented in Appendix A.2.1. Note that the premium levels $\left(f i p_{c, t}\right)$ are considered as parameters for the lower-level agents. The KKT-conditions (Eqs. 32 - 48) fulfill a set of requirements that enable to cast it into a single-objective formulation (Poncelet et al., 2019; Gabriel et al., 2012). This equivalent optimization problem is presented in Appendix A.2.2, and the reader can confirm that its KKT-conditions correspond to those of Appendix A.2.1. As a consequence, the lower-level equilibrium can be solved fast via the equivalent optimization problem, as long as the feed-in premium levels are parameters.

For the autarky case, one can iteratively adapt the national support levels (defined by either Eq. 15 or Eq. 16) and resolve the equivalent optimization problem up till the national renewable energy quota is fulfilled. Specifically, one could update the national support levels in the next iteration based on the excess or deficit of yearly renewable energy generation. In practice, however, a small increase or decrease in the support level can have a strong effect on the yearly renewable electricity generation (e.g. slightly increasing the support level could make an entire new location fully viable). We therefore chose to add the national renewable energy quota (Eq. 17) to the equivalent problem (Appendix A.2.2). The support level in the objective then is updated up till the dual variable of the renewable energy quota is sufficiently small. Put differently, we update the support level based on dual errors, and not on primal errors. The same approach can be applied for the joint auction case where one single support level needs to be set to fulfill one global renewable energy target.

To model the third cooperation variant (MSC), we wrap an outer iteration loop around the autarky procedure mentioned above. In this outer iteration loop, the national targets are adjusted based on a greedy algorithm that aims to minimize the total cost (Eq. 24). Such an approach works quite well as long as the amount of Member States remains small, which is the main reason why we only include four countries. It must be noted that this problem is not necessarily convex and can have multiple solutions (see e.g. Fig. 3). We therefore ran the algorithm multiple times with different starting points and different implementations of the greedy algorithm. The results presented in the body of this paper are those with the lowest system cost. Nonetheless, the multiple equilibria were 
very much alike and the maximum policy cost differences within the same case was about $1 \%$. The existence of multiple equilibriums does therefore not change the conclusions presented in the main body.

\section{A.2.1 Lower-level KKT-conditions}

$$
\begin{aligned}
& V C_{s}+\lambda_{c, s, t}^{c}-p_{c, t}^{e} \geq 0 \quad \perp \quad y_{c, s, t} \geq 0 \quad \forall c, s, t \\
& \bar{Y}_{c, s, t}-y_{c, s, t} \geq 0 \quad \perp \quad \lambda_{c, s, t}^{c} \geq 0 \quad \forall c, s, t \\
& \lambda_{c, t}^{r}-p_{c, t}^{e}-\text { fip }_{c, t} \geq 0 \quad \perp \quad x_{c, t} \geq 0 \quad \forall c, t \\
& C^{i n v}+\theta_{c} I_{c, i} C_{i}^{g r i d}+\delta_{i}-\sum_{c, t} P_{i, t} I_{c, i} \lambda_{c, t}^{r} \geq 0 \quad \perp \quad n_{i} \quad \geq 0 \quad \forall i \\
& \sum_{i} P_{i, t} I_{c, i} n_{i}-x_{c, t} \geq 0 \quad \perp \quad \lambda_{c, t}^{r} \geq 0 \quad \forall c, t \\
& \bar{N}_{i}-n_{i} \geq 0 \quad \perp \quad \delta_{i} \quad \geq 0 \quad \forall i \\
& \beta_{c, t}^{d c}-p_{c, t}^{e}+\frac{\gamma_{c, t}}{\eta} \geq 0 \quad \perp \quad s_{c, t}^{d c} \geq 0 \quad \forall c, t \\
& \beta_{c, t}^{c}+p_{c, t}^{e}-\eta \gamma_{c, t} \geq 0 \quad \perp \quad s_{c, t}^{c} \geq 0 \quad \forall c, t \\
& \beta_{c, t}^{e}+\gamma_{c, t}-\gamma_{c, t-1} \geq 0 \quad \perp \quad e_{c, t} \geq 0 \quad \forall c, t \\
& \bar{S}_{c, t}^{d c}-s_{c, t}^{d c} \geq 0 \quad \perp \quad \beta_{c, t}^{d c} \geq 0 \quad \forall c, t \\
& \bar{S}_{c, t}^{c}-s_{c, t}^{c} \geq 0 \quad \perp \quad \beta_{c, t}^{c} \geq 0 \quad \forall c, t \\
& \bar{E}_{c, t}-e_{c, t} \geq 0 \quad \perp \quad \beta_{c, t}^{e} \geq 0 \quad \forall c, t \\
& e_{c, t}-e_{c, t-1}-\eta s_{c, t}^{c}+\frac{s_{c, t}^{d c}}{\eta}=0 \quad\left(\gamma_{c, t}\right) \quad \forall c, t \\
& \bar{F}_{l}^{p}-f_{l, t} \geq 0 \quad \perp \quad \epsilon_{l, t}^{p} \quad \geq 0 \quad \forall l, t \\
& \bar{F}_{l}^{n}+f_{l, t} \geq 0 \quad \perp \quad \epsilon_{l, t}^{n} \quad \geq 0 \quad \forall l, t \\
& \sum_{c} A_{c, l} p_{c, t}^{e}-\epsilon_{l, t}^{p}+\epsilon_{l, t}^{n}=0 \quad\left(f_{l, t}\right) \quad \forall l, t \\
& \sum_{s} y_{c, s, t}+x_{c, t}+s_{c, t}^{d c}-s_{c, t}^{c}+\sum_{l} A_{c, l} f_{l, t}-D_{c, t}=0 \quad\left(p_{c, t}^{e}\right) \quad \forall c, t
\end{aligned}
$$




\section{A.2.2 Lower-level Equivalent optimization problem}

$$
\begin{aligned}
& \max _{\substack{y_{c}, t, x_{c, t}, n_{i}, s_{c, t}, s_{c, t}^{c}, e_{c, t}, f_{l, t}}} \sum_{c, t} f i p_{c, t} x_{c, t}-\sum_{i}\left(C^{i n v}+\theta_{c} I_{c, i} C_{i}^{g r i d}\right) n_{i}-\sum_{c, s, t} V C_{s} y_{c, s, t} \\
& \text { s.t. } 0 \leq y_{c, s, t} \leq \bar{Y}_{c, s, t} \quad\left(\lambda_{c, s, t}^{c}\right) \quad \forall c, s, t \\
& 0 \leq x_{c, t} \leq \sum_{i} P_{i, t} I_{c, i} n_{i} \quad\left(\lambda_{c, t}^{r}\right) \quad \forall c, t \\
& 0 \leq n_{i} \leq \bar{N}_{i} \quad\left(\delta_{i}\right) \quad \forall i \\
& 0 \leq s_{c, t}^{d c} \leq \bar{S}_{c, t}^{d c} \quad\left(\beta_{c, t}^{d c}\right) \quad \forall c, t \\
& 0 \leq s_{c, t}^{c} \leq \bar{S}_{c, t}^{c} \quad\left(\beta_{c, t}^{c}\right) \quad \forall c, t \\
& 0 \leq e_{c, t} \leq \bar{E}_{c, t} \quad\left(\beta_{c, t}^{e}\right) \quad \forall c, t \\
& e_{c, t}=e_{c, t-1}+\eta s_{c, t}^{c}-\frac{s_{c, t}^{d c}}{\eta} \quad\left(\gamma_{c, t}\right) \quad \forall c, t \\
& \bar{F}_{l}^{p}-f_{l, t} \geq 0 \quad\left(\epsilon_{l, t}^{p}\right) \quad \forall l, t \\
& \bar{F}_{l}^{n}+f_{l, t} \geq 0 \quad\left(\epsilon_{l, t}^{n}\right) \quad \forall l, t \\
& \sum_{s} y_{c, s, t}+x_{c, t}+s_{c, t}^{d c}-s_{c, t}^{c}+\sum_{l} A_{c, l} f_{l, t}=D_{c, t} \quad\left(p_{c, t}^{e}\right) \quad \forall c, t
\end{aligned}
$$

\section{A.3 Case study data}

Most of the wind energy parameters are determined by following the same methodology as in Meus et al. (2021). We draw upon the work of Ryberg et al. (2019) which estimates the future European onshore wind energy potential based on a turbine placement algorithm. Essentially, the authors first select suitable turbines areas (i.e. excluding airports, protected sites, etc.) and then heuristically pack these areas with as many turbines as possible subject to a minimal turbine separation constraint. Their approach leads to approximately 580,000 potential turbines locations over the four countries for which the data has been made publicly available. We then cluster these individual turbines into 5,000 individual sites based on a k-means clustering algorithm to reduce computational effort. Each individual cluster corresponds to a potential site, whilst the amount of turbines allocated to that cluster constitutes the maximum amount of turbines that can be installed at that site.

To obtain the maximum power output per location and per time-step ( $P_{i, t}$ in Eq. 4$)$, one needs to obtain wind speed profiles at the individual sites, scale these up to match the turbine's hub height and then convert these via a power curve function. To do so, we again follow the approach of Ryberg et al. (2019) and refer to their work for the details and data sources. The methodology does require the wind turbine specifications and we therefore adopt the average characteristics of onshore turbines that are currently being installed, i.e. a nominal power of $2.6 \mathrm{MW}$, a hub height of $110 \mathrm{~m}$ and a rotor diameter of $110 \mathrm{~m}$ (IRENA, 2019a).

IRENA (2019b) reports a total installation $\operatorname{cost}^{19}$ of $1,620 € / \mathrm{kW}$, which we annualize using an economic lifetime of 20 years and an interest rate of $6 \%$. They additionally report an operation and maintenance cost around $36 € /(k W y)$. As such, the annualized cost for installing and exploiting a wind turbine, net of the grid connection costs, can be written as:

$$
C^{i n v}=\delta\left(1,620-\overline{C^{\text {grid }}}\right)+36 \quad[€ /(k W y)]
$$

\footnotetext{
${ }^{19}$ Including costs for equipment, licensing, installation, grid-connection, etc.
} 
Table A1: Techno-economic parameters of the power plant technologies. VOM = variable operation and maintenance, $\mathrm{VC}=$ variable cost. Compiled from IEA and NEA (2015); Van den Bergh and Delarue (2015); Hirth (2017); Ward et al. (2019).

\begin{tabular}{lcccccc}
\hline Type & $\begin{array}{c}\text { Efficiency } \\
{\left[M W h_{e} / M W h_{t h}\right]}\end{array}$ & $\begin{array}{c}\text { Fuel cost } \\
{\left[€ / M W h_{t h}\right]}\end{array}$ & $\begin{array}{c}\text { Emission intensity } \\
{\left[t C O_{2} / M W h_{t h}\right]}\end{array}$ & $\begin{array}{c}\text { VOM cost } \\
{\left[€ / M W h_{e}\right]}\end{array}$ & $\begin{array}{c}\text { Carbon price } \\
{\left[€ / t C O_{2}\right]}\end{array}$ & $\begin{array}{c}\text { VC } \\
{\left[€ / M W h_{e}\right]}\end{array}$ \\
\hline Nuclear & 0.33 & 3 & 0 & 8 & 24.5 & 17 \\
Lignite & 0.38 & 3 & 0.41 & 3 & 24.5 & 37 \\
Coal & 0.39 & 10 & 0.34 & 3 & 24.5 & 50 \\
CCGT & 0.54 & 19 & 0.19 & 2 & 24.5 & 46 \\
OCGT & 0.39 & 19 & 0.19 & 2 & 24.5 & 63 \\
\hline
\end{tabular}

Table A2: Average available capacities in GW. Values between brackets represent the minimum and maximum available capacity. Compiled from Platts (2013); Open Power System Data (2019); ENTSO-E (2020).

\begin{tabular}{llllll}
\hline & Nuclear & Lignite & Coal & CCGT & OCGT \\
\hline BE & $3.1(1.0-4.9)$ & $0.0(0.0-0.0)$ & $0.0(0.0-0.0)$ & $4.6(3.1-5.1)$ & $0.9(0.4-1.0)$ \\
NL & $0.5(0.0-0.5)$ & $0.0(0.0-0.0)$ & $3.0(0.0-4.6)$ & $15.6(13.3-16.3)$ & $1.9(1.3-2.0)$ \\
FR & $46.8(31.9-58.7)$ & $0.0(0.0-0.0)$ & $3.0(1.6-4.0)$ & $9.8(7.2-10.9)$ & $0.8(0.6-0.8)$ \\
DE & $8.1(9.5-13.9)$ & $18.1(13.9-21.0)$ & $20.7(14.2-23.8)$ & $16.3(12.1-19.6)$ & $9.6(7.0-10.6)$ \\
\hline
\end{tabular}

Table A3: Storage parameters taken from Platts (2013); Geth et al. (2015).

\begin{tabular}{crrrr}
\hline Country & Max charging [MW] & Max discharging [MW] & Max energy [MWh] & $\eta[-]$ \\
\hline BE & 1,209 & 1,308 & 5,800 & 0.866 \\
NL & 0 & 0 & 0 & 0.866 \\
FR & 4,375 & 5,565 & 83,472 & 0.866 \\
DE & 6,165 & 6,544 & 38,062 & 0.866 \\
\hline
\end{tabular}

Table A4: Net transfer capacities [MW] taken from ENTSO-E (2020) (forecasted transfer capacities).

\begin{tabular}{lrr}
\hline $\mathrm{C}_{1} / \mathrm{C}_{2}$ & $\mathrm{C}_{1} \rightarrow \mathrm{C}_{2}$ & $\mathrm{C}_{2} \rightarrow \mathrm{C}_{1}$ \\
\hline $\mathrm{BE} / \mathrm{NL}$ & 1,500 & 1,500 \\
$\mathrm{BE} / \mathrm{FR}$ & 1,600 & 2,300 \\
$\mathrm{DE} / \mathrm{NL}$ & 2,450 & 2,450 \\
$\mathrm{DE} / \mathrm{FR}$ & 1,200 & 1,500 \\
\hline
\end{tabular}

Table A5: National additional wind electricity generation targets.

\begin{tabular}{lcc}
\hline & Absolute target [TWh/y] & Relative to national demand [\%] \\
\hline $\mathrm{BE}$ & 2.4 & 2.7 \\
$\mathrm{NL}$ & 1.8 & 1.5 \\
$\mathrm{FR}$ & 18.9 & 4.0 \\
$\mathrm{DE}$ & 36.1 & 7.1 \\
\hline
\end{tabular}


Where $\delta$ represents the annuity payment factor and $\overline{C^{\text {grid }}}$ the average grid connection cost. Note that the 1,620-value reported by IRENA (2019b) includes the grid connection costs and that this component should be filtered out to fit the mathematical formulation (Section 4.2). We therefore have to subtract the average grid connection cost (which is discussed below). Note also that this provides a cost estimate in $€ / \mathrm{kW}$, whilst our mathematical formulation includes the cost in $€ /$ turbine. The resulting cost from Eq. 60 thus needs to be multiplied by the nominal turbine power.

Grid connection costs per cluster $\left(C_{i}^{\text {grid,cluster }}\right)$ can be calculated via an empirical relationship developed by Eberle et al. (2019):

$$
C_{i}^{\text {grid, } \text { cluster }}=\left(1,176 V_{i}+218,257\right)\left(\frac{d_{i}}{1.609}\right)^{0.8937}+18,115 V_{i}+165,994
$$

Where $V_{i}$ is the interconnection voltage (in $\mathrm{kV}$ ) and $d_{i}$ the distance to the interconnection (in $\mathrm{km}$ ). Both values can be extracted from the SciGRID dataset (Matke et al., 2016), which comprises the topology and line characteristics of the European transmission system. We first determine which transmission line is closest to a cluster's centroid and then insert the voltage level of that closest line in Eq. 61, along with the distance to that line.

We aim to allocate these grid costs to single turbines and not to clusters (Subsection 4.2). The most straightforward approach would be to divide the per-cluster connection cost by the maximum amount of turbines at that cluster. Unfortunately, such an approach interacts poorly with our clustering algorithm. Indeed, clusters can contain fewer than 10 but also more than 200 turbines. In this last case, the individual turbines encompass quite a large area and will probably require multiple grid connections. This cannot be recognized when simply dividing by the amount of turbines per cluster and the approach would bias the results towards sites encapsulating many turbines ${ }^{20}$. Even more troublesome, the average grid connection costs would depend on the amount of clusters ${ }^{21}$. We therefore want the per-turbine connection cost to be independent on the amount of turbines that can be installed at that site. It additionally is required that the calculated per-turbine connection costs reflect the actual average value. Both conditions can be formulated as:

$$
\begin{aligned}
C_{i}^{\text {grid }} & =\frac{C_{i}^{\text {grid,cluster }}}{N^{e q}} \\
\frac{\sum_{i} \overline{N_{i}} C_{i}^{\text {grid }}}{\sum_{i} \overline{N_{i}}} & =\overline{C^{\text {grid }}}
\end{aligned}
$$

Eq. 62 states that the per-turbine connection cost $\left(C_{i}^{\text {grid }}\right)$ at location $i$ can be calculated by dividing the per-cluster connection cost at that location by a constant $\left(N^{e q}\right) . \overline{N_{i}}$ represents the amount of turbines that can be installed at site $i$ and Eq. 63 therefore states that the average per-turbine grid connection cost should reflect the actual mean value. Using these equations, it is possible to calculate $C_{i}^{\text {grid }}$ and $N^{e q}$ (all other entries are known). $N^{e q}$ can be interpreted as an equivalent project size, i.e. the average amount of turbines per grid-connection. Suppose for instance that a cluster comprises 100 turbines and that $N^{e q}$ equals 20. Eq. 62 states that the per-cluster grid cost should be divided by the equivalent project size (20) and not by the amount of turbines at that cluster (100). Alternatively, one can say that this cluster requires 5 grid connections and that the total connection cost (i.e. five times the per-cluster connection cost) is allocated evenly to the 100 individual turbines. Eq. 63 also presents an opportunity to recalibrate the average grid connection cost to European values (because the empirical relationship in Eq. 61 is based on US values). As such, we set $\overline{C^{g r i d}}$ to $125 € / \mathrm{kW}$ based

\footnotetext{
${ }^{20}$ Because the grid-connection cost per cluster would be divided over many turbines.

${ }^{21}$ I.e. doubling the amount of clusters would approximately double the average grid connection cost per turbine. Consider for instance the situation where each cluster comprises exactly one turbine. The entire per-cluster connection cost calculated via Eq. 61 would then be fully allocated to that single turbine. If every cluster instead comprises two turbines, this per-cluster connection cost (which will be about the same) could be shared across two turbines.
} 
on the references compiled by Hirth and Müller (2016). The average value is annualized as before.

This is an approximation that should not be used in actual planning exercises. First, it is probably inaccurate to allocate a single grid-connection cost to clusters comprising more than 100 turbines as these typically require multiple connections, each with a different cost. Second, this approach cannot recognize that larger projects (e.g. 10 turbines) and smaller projects (e.g. 5 turbines) both allocate the grid connection cost based on the project size. The connection cost of the larger project can be shared over 10 turbines, whilst the one of the smaller project can only be shared over 5 turbines. This cannot be included due to the clustering approach (see above), which in turn is required for computational reasons. Nonetheless, our method is able to conceive grid connection cost values that approach the mean value (Eq. 63) and contain a realistic spread based on distance and connection voltage (Eq. 61). We therefore deem the approach sufficiently accurate for policy analyses.

\section{A.4 Country-level distributional effects}

As mentioned in the main body, the model allows to assess country-level distributional implications. In what follows, we first introduce the metric and then discuss the additional results.

\section{A.4.1 Metric}

To assess country-level distributional implications, we calculate the additional cost for a country to meet the renewable energy target:

$$
\begin{aligned}
T C C_{c}^{k} & =\sum_{i} I_{c, i}\left(C^{i n v}+C_{i}^{g r i d}\right) n_{i}^{k}+\sum_{s, t} V C_{s} y_{c, s, t}^{k}+E C_{c}^{k}+C R_{c}^{k}+R C_{c}^{k} \\
A C C_{c}^{k} & =T C C_{c}^{k}-T C C_{c}^{0}
\end{aligned}
$$

Eq. 64 defines the total cost of country $c$ for case $k$. The first two terms are similar as in Eq. 28 but confined to the costs occurring in country $c$. The final three terms are transfers relating to electricity and renewable electricity trade. As before, we are only considering the additional country's cost due to the renewable electricity target and subtract the cost for meeting electricity demand (see Eq. 65). The three transfer components can be formulated as:

$$
\begin{aligned}
E C_{c}^{k} & =\sum_{t}\left[p_{c, t}^{e, k} \sum_{l} A_{c, l} f_{l, t}^{k}\right] \\
C R_{c}^{k} & =-\frac{1}{2} \sum_{l, t}\left|A_{c, l} f_{l, t}^{k} \sum_{c^{\prime}} A_{c^{\prime}, l}\left(p_{c, t}^{e, k}-p_{c^{\prime}, t}^{e, k}\right)\right| \\
R C_{c}^{k} & =p^{r, k}\left(\text { Target }_{c}-\sum_{t} x_{c, t}^{k}\right)
\end{aligned}
$$

Where $E C_{c}^{k}$ are the costs from importing electricity, $C R_{c}^{k}$ are the congestion rents in the electricity market and $R C_{c}^{k}$ are the costs from importing renewable electricity. These components are defined using typical market conventions.

The final element that remains to be defined is this transfer price for renewable energy ( $p^{r, k}$ in Eq. 68), which depends on the cooperation variant and generally follows the same conventions as introduced in Section 3. When harmonizing support levels, we follow the principles of the Union renewable financing mechanism, i.e. the EU-wide tender. The Revised Renewable Energy Directive declares that the renewable energy generated by installations financed via this mechanism will be statistically attributed to the participating Member States based on their reflective payments (EU, 2018a). Formally: 


$$
p^{r, k} \sum_{c} \operatorname{Target}_{c}=\sum_{c, t} f i p_{c, t}^{k} x_{c, t}^{k}
$$

Eq. 69 states that (i) a Member State's contribution is proportional to their individual target, and that (ii) all payments (left-hand side) must cover the total support cost (right-hand side). Recall that the feed-in premium variable only includes the direct cost for the policy makers, and may or may not cover grid connection charges (Subsection 4.2). These transfers might thus be underpriced if grid connection costs are not consistently financed by renewable investors.

For the third cooperation case (MSC in Table 1) it seems sensible to use the harmonized marginal support cost as transfer price. If national support instruments are perfect (i.e. renewable investors are rewarded fixed feed-in premiums and are charged grid connection costs), the marginal support cost equals the fixed premium level and can directly be extracted from the model output. The MSC is not readily available from the model output for the other three cases, but can nonetheless be approximated by marginally increasing the global renewable energy quota and rerunning the model. The increase in the total system cost, divided by the increase in the renewable quota, then approximates the marginal support cost (i.e. the definition of the MSC, Section 3$)^{22}$.

\section{A.4.2 Additional Results}

Table A6 presents the additional country cost as defined by Eq. 65 for France and Germany. There are three noteworthy items. First, the German additional country cost is significantly higher than the French one for all cases. This can mostly be explained by Germany's more ambitious targets for onshore wind energy (Table A5). Even with renewable cooperation, Germany would therefore finance a relatively larger part of the global target.

Second, by comparing the country-level costs in autarky to the ones with perfect renewable cooperation (MSC), one can notice that Germany will see a cost decrease when engaging in renewable cooperation, but France will see a cost increase. France will thus lose when cooperating optimally. This effect cannot be captured by the single-sector model presented in Section 3 because additional distributional shifts occur within the electricity market. In what follows, we briefly describe the underlying reason. Interested readers are referred to Unteutsch (2014) or Meus et al. (2019) for a formal derivation. The distributional transfers between countries arise from changing electricity prices and their effect on the terms of trade in the electricity market. Consider the French-German interconnection. It can be shown that France receives the average of the French and German electricity prices per unit of exported electricity ${ }^{23}$. Introducing perfect renewable trade will move RES-E capacity from Germany to France. Accordingly, German electricity prices will increase whilst French prices decrease. In our case study, the latter effect dominates and the average electricity price will decrease as well. Because France is a net exporter, and because renewable cooperation causes a drop in average electricity prices, France receives less for its electricity exports whilst Germany has to pay less for its imports. There thus is a distributional shift between countries via electricity trading that can offset the national gains of renewable cooperation. It is not guaranteed that all countries will individually benefit from renewable energy cooperation, and this case study illustrates that such distributional concerns have to be taken into account.

Third, the SL-column in Table A6 illustrates the effect of mispricing renewable transfers. These transfer prices are presented in Table A7. For case 1, the transfer prices equal the marginal support cost, which is optimal (besides perhaps the distributional shifts in the electricity market mentioned above). In case 2, the transfers are priced too low because France and Belgium do not

\footnotetext{
${ }^{22}$ This approach proved to be sufficiently accurate. For instance, the MSC extracted via this method perfectly corresponds to the harmonized premium level if national policies are perfect.

${ }^{23}$ I.e. the sum of Eqs. 66 and 67.
} 
Table A6: Additional country cost in $M € / y$ for France and Germany.

\begin{tabular}{cccccccc} 
& \multicolumn{3}{c}{ France } & & \multicolumn{3}{c}{ Germany } \\
\cline { 2 - 4 } \cline { 6 - 8 } Case & Autarky & SL & MSC & & Autarky & SL & MSC \\
\hline 1 & 48 & 56 & 56 & & 231 & 192 & 192 \\
2 & 50 & 99 & 55 & & 232 & 170 & 194 \\
3 & 48 & 24 & 57 & & 232 & 389 & 192 \\
4 & 50 & 69 & 57 & & 232 & 432 & 192 \\
\hline
\end{tabular}

Table A7: Renewable transfer price in $€ / M W h$.

\begin{tabular}{ccc} 
& \multicolumn{2}{l}{ Cooperation variant } \\
\cline { 2 - 3 } Case & SL & MSC \\
\hline 1 & 8.6 & 8.6 \\
2 & 7.6 & 8.7 \\
3 & 15.4 & 8.5 \\
4 & 15.1 & 8.6 \\
\hline
\end{tabular}

allocate their grid costs to renewable investors. The required support level is lower and the transfer prices correspondingly are lower as well (Eq. 69). France exports renewable electricity, but the transfer prices cannot cover their grid connection expenditures. The underpricing of renewable transfers hurts the exporter (France) for the benefit of the importer (Germany). The country-level costs are somewhat more difficult to interpret when cooperation is based on a sliding feed-in premium system. As mentioned, this is highly inefficient so the country-level costs generally increase compared to the optimum. The exception is France's country-level cost for case 3, which is relatively low. The excessive support costs necessary to finance France's renewable capacity also set a transfer price that is quite high, see Table A7. It can be shown that renewable transfers in this case are overpriced, benefiting the exporter (France) at the expense of the importer (Germany).

Using a simple price system thus implies two country-level distributional concerns. First, renewable cooperation may imply shifts via the electricity market and second, imperfect national policies cause an over- or underpricing of renewable transfers. One may thus need an additional instrument, e.g. lumpsum transfers, to incentivize all players to participate in the trading game. One can use different concepts in cooperative game theory to allocate the gains from trade and make sure that all countries gain (see e.g. Busch and Ortner (2019)).

\section{REFERENCES}

ACER/CEER (2017). "Annual Report on the Results of Monitoring the Internal Electricity and Natural Gas Markets in 2016" . ACER/CEER (2018). "Annual Report on the Results of Monitoring the Internal Electricity and Natural Gas Markets in 2017" . ACER/CEER (2019). "Annual Report on the Results of Monitoring the Internal Electricity and Natural Gas Markets in 2018" . Anselm, E., K. Tarun, and L. Hirth (2020). "Locational Investment Signals : How to Steer the Siting of New Generation Capacity in Power Systems ?” The Energy Journal 41(6): 281-304.

Aune, F. R., H. M. Dalen, and C. Hagem (2012). "Implementing the EU renewable target through green certificate markets" Energy Economics 34(4): 992-1000.

Benja, M., M. Jégard, F. Monforti-Ferrario, J. Dallemand, N. Taylor, V. Motola, and R. Sikkerma (2017). "Renewables in the EU: the support framework towards a single market" JRC. doi:http://dx.doi.org/10.2760/521847.

Bjørnebye, H., C. Hagem, and A. Lind (2018). "Optimal location of renewable power" Energy 147(714): 1203-1215 doi:10.1016/j.energy.2018.01.058.

Busch, S. and A. Ortner (2019). From National to Cross-Border Support of Renewable Electricity in the European Union Springer International Publishing, Cham ISBN 978-3-030-03374-3 207-225 doi:10.1007/978-3-030-03374-3_11.

Caldés, N., P. Del Río, Y. Lechón, and A. Gerbeti (2018). "Renewable Energy Cooperation in Europe: What Next? Drivers and Barriers to the Use of Cooperation Mechanisms" Energies 12(1). 
Capros, P., L. Mantzos, L. Parousos, N. Tasios, G. Klaassen, and T. Van Ierland (2011). "Analysis of the EU policy package on climate change and renewables" Energy Policy 39(3): 1476-1485.

CEER (2016). "Key support elements of RES in Europe: moving towards market integration.” CEER report C15-SDE-49-03. Available at: https://www.ceer.eu/documents/104400/-/-/28b53e80-81cf-f7cd-bf9b-dfb46d471315.

D'haeseleer, W., L. de Vries, C. Kang, and E. Delarue (2017). "Flexibility Challenges for Energy Markets: Fragmented Policies and Regulations Lead to Significant Concerns" IEEE Power and Energy Magazine 15(1): 61-71 ISSN 1540-7977 doi:10.1109/MPE.2016.2629742.

Eberle, A., O. Roberts, A. Key, P. Bhaskar, and K. Dykes (2019). "NREL's Balance-of-System Cost Model for Land-Based Wind" Technical Report NREL/TP-6A20-72201. Available at: https://www.nrel.gov/docs/fy19osti/72201.pdf . Ecofys and eclareon (2018). "Cross-Border Renewables Cooperation. Study on behalf of Agora Energiewende" .

ENTSO-E (2019). ““'Overview of Transmission Tariffs in Europe: Synthesis 2019” Available at: https://www . entsoe. eu/ publications/market-reports/\#european-transmission-tariffs.

ENTSO-E (2020). "ENTSO-E Transparency Platform” Available at: https://transparency. entsoe.eu/.

EU (2009). "Directive 2009/28/EC of the European Parliament and of the council".

EU (2018a). "Directive 2018/2001 of the European Parliament and of the Council".

EU (2018b). "Regulation (EU) 2018/1999 of the European Parliament and of the Council".

European Commission (2020). "National energy and climate plans (NECPs)." [online] Available at: https://ec. europa. eu/energy/en/topics/energy-strategy/national-energy-climate-plans (February 2020) .

Gabriel, S. A., A. J. Conejo, J. D. Fuller, B. F. Hobbs, and C. Ruiz (2012). Complementarity Modeling in Energy Markets Springer Publishing Company, Incorporated ISBN 1441961224.

Geth, F., T. Brijs, J. Kathan, J. Driesen, and R. Belmans (2015). “An overview of large-scale stationary electricity storage plants in Europe: Current status and new developments" Renewable and Sustainable Energy Reviews 52: 1212-1227 doi:10.1016/j.rser.2015.07.145.

González, J. S. and R. Lacal-Arántegui (2016). "A review of regulatory framework for wind energy in European Union countries: Current state and expected developments" Renewable and Sustainable Energy Reviews 56(2016): 588-602 doi:10.1016/j.rser.2015.11.091.

Green, R., D. Staffell, and G. Strbac (2016). "Market Design for Long-Distance Trade in Renewable Electricity” The Energy Journal 37(1): 5-22.

Hirth, L. (2013). "The market value of variable renewables. The effect of solar wind power variability on their relative price" Energy Economics 38: 218-236 doi:10.1016/j.eneco.2013.02.004.

Hirth, L. (2017). "The European Electricity Model Market EMMA Model Documentation." Available at: https:// neon-energie.de/emma-documentation.pdf .

Hirth, L. and S. Müller (2016). "System-friendly wind power. How advanced wind turbine design can increase the economic value of electricity generated through wind power" Energy Economics 56: 51-63 doi:10.1016/j.eneco.2016.02.016.

Hirth, L., F. Ueckerdt, and O. Edenhofer (2015). "Integration costs revisited - An economic framework for wind and solar variability" Renewable Energy 74: 925-939 doi:10.1016/j.renene.2014.08.065.

Hirth, L. and I. Ziegenhagen (2015). "Balancing power and variable renewables: Three links" Renewable and Sustainable Energy Reviews 50: 1035-1051 doi:10.1016/j.rser.2015.04.180.

Hu, J., R. Harmsen, W. Crijns-Graus, E. Worrell, and M. van den Broek (2018). "Identifying barriers to large-scale integration of variable renewable electricity into the electricity market: A literature review of market design" Renewable and Sustainable Energy Reviews 81(91): 2181-2195 doi:10.1016/j.rser.2017.06.028.

Huntington, S. C., P. Rodilla, I. Herrero, and C. Batlle (2017). "Revisiting support policies for RES-E adulthood: Towards market compatible schemes" Energy Policy 104: 474-483 doi:10.1016/j.enpol.2017.01.006.

IEA and NEA (2015). "Projected costs of generating electricity, 2015 edition." Available at: https://www.oecd-nea.org/ ndd/pubs/2015/7057-proj-costs-electricity-2015.pdf .

IRENA (2019a). "Future of Wind: Deployment, investment, technology, grid integration and socio-economic aspects (A Global Energy Transformation paper)" International Renewable Energy Agency, Abu Dhabi. Available at: https: //www. irena.org/publications/2019/0ct/Future-of-wind (February 2020).

IRENA (2019b). "Renewable Power Generation Costs in 2018" International Renewable Energy Agency, Abu Dhabi. Available at: https://www . irena.org/publications/2019/May/Renewable-power-generation-costs-in-2018 (February 2020).

Jägemann, C., M. Fürsch, S. Hagspiel, and S. Nagl (2013). "Decarbonizing Europe's power sector by 2050 - Analyzing the economic implications of alternative decarbonization pathways" Energy Economics 40: 622-636.

Klessmann, C., E. De Visser, F. Wigand, M. Gephart, G. Resch, S. Busch, and T. Vienna (2014). "Cooperation between EU Member States under the RES Directive" EU project DESNL13116: Task 1 report. 
Klinge Jacobsen, H., L. L. Pade, S. T. Schröder, and L. Kitzing (2014). "Cooperation mechanisms to achieve EU renewable targets" Renewable Energy 63: 345-352 doi:10.1016/j.renene.2013.09.035.

Matke, C., W. Medjroubi, and D. Kleinhans (2016). "SciGRID: An Open Source Reference Model for the European Transmission Network (v0.2)" Available at: http://www. scigrid.de .

Meus, J., S. De Vits, N. S'heeren, E. Delarue, and S. Proost (2021). "Renewable electricity support in perfect markets : Economic incentives under diverse subsidy instruments" Energy Economics 94: 105066 doi:10.1016/j.eneco.2020.105066.

Meus, J., K. Van den Bergh, E. Delarue, and S. Proost (2019). "On international renewable cooperation mechanisms: The impact of national RES-E support schemes” Energy Economics 81: 859-873 doi:10.1016/j.eneco.2019.05.016.

Newbery, D., M. G. Pollitt, R. A. Ritz, and W. Strielkowski (2018). "Market design for a high-renewables European electricity system” Renewable and Sustainable Energy Reviews 91(July 2017): 695-707 doi:10.1016/j.rser.2018.04.025.

Newbery, D. M. (2018). "What future(s) for liberalized electricity markets: Efficient, equitable or innovative?" Energy Journal 39(1): 1-27 doi:10.5547/01956574.39.1.dnew.

Olmos, L. and I. J. Pérez-Arriaga (2009). "A comprehensive approach for computation and implementation of efficient electricity transmission network charges" Energy Policy 37: 5285-5295.

Open Power System Data (2018). "Data Package Converntional Power plants. Version 2018-12-20" Available at: https:// doi.org/10.25832/conventional_power_plants/2018-12-20. (Primary data from various sources, for a complete list see URL) .

Open Power System Data (2019). "Data Package Time series. Version 2019-06-05” Available at: https://doi .org/10. 25832/conventional_power_plants/2018-12-20. (Primary data from various sources, for a complete list see URL)

Ovaere, M. and K. Gillingham (2019). "The Heterogeneous Value of Solar and Wind Energy: Empirical Evidence from the United States and Europe".

Pahle, M., W. P. Schill, C. Gambardella, and O. Tietjen (2016). "Renewable energy support, Negative prices, and real-Time pricing” Energy Journal 37(SpecialIssue3): 147-169 doi:10.5547/01956574.37.SI3.mpah.

Perez, A. P., E. E. Sauma, F. D. Munoz, and B. F. Hobbs (2016). "The economic effects of interregional trading of Renewable Energy certificates in the U.S. WECC” Energy Journal 37(4): 267-295 doi:10.5547/01956574.37.4.aper.

Platts (2013). "World electric power plant database - Europe".

Poncelet, K., S. Kaminski, and E. Delarue (2019). "Ability and limitations of optimization models for computing the equilibrium in competitive energy markets." KU Leuven, TME Branch Working Paper EN2019-09. Available at: https : //www.mech.kuleuven.be/en/tme/research/energy_environment/Pdf/wp-en2019-09.

Ragwitz, M., A. Held, G. Resch, T. Faber, R. Haas, C. Huber, P. E. Morthorst, S. G. Jensen, R. Coenraads, M. Voogt, G. Reece, I. Konstantinaviciute, and B. Heyder (2007). "Assessment and optimisation of renewable energy support schemes in the European electricity market” Tech rep, Project supported by the European Commission .

Rijksoverheid (2020). "Agreement for Statistical Transfer of Energy from renewable sources" Available at: https://www.rijksoverheid.nl/documenten/convenanten/2020/06/19/ agreement-for-statistical-transfer-of-energy-from-renewable-sources.

Ryberg, D. S., D. G. Caglayan, S. Schmitt, J. Linßen, D. Stolten, and M. Robinius (2019). "The future of European onshore wind energy potential: Detailed distribution and simulation of advanced turbine designs" Energy 182: 1222-1238 doi:10.1016/j.energy.2019.06.052.

Saguan, M. and L. Meeus (2014). "Impact of the regulatory framework for transmission investments on the cost of renewable energy in the EU" Energy Economics 43: 185-194.

Staffell, I. and S. Pfenninger (2016). "Using bias-corrected reanalysis to simulate current and future wind power output" Energy 114: 1224-1239 doi:10.1016/j.energy.2016.08.068.

Turvey, R. (2006). "Short \& long run transmission incentives for generation location" (March) wP06-004. Center for Energy and Environmental Policy Research.

Unteutsch, M. (2014). "Redistribution effects resulting from cross-border cooperation in support for renewable energy" $E W I$ Working Paper, No. 14/01.

Unteutsch, M. and D. Lindenberger (2014). "Promotion of Electricity from Renewable Energy in Europe Post 2020: The Economic Benefits of Cooperation" Zeitschrift für Energiewirtschaft 38(1): 47-64.

Van den Bergh, K. and E. Delarue (2015). "Cycling of conventional power plants: Technical limits and actual costs" Energy Conversion and Management 97: 70-77 doi:10.1016/j.enconman.2015.03.026.

Von Blüchen, F., M. Gephart, F. Wigand, V. Anatolites, J. Winkler, A. Held, J. K. Sekamane, and L. Kitzing (2019). "Design options for cross-border auctions." Aures report D6.1 .

Voogt, M. H. and M. A. Uyterlinde (2006). "Cost effects of international trade in meeting EU renewable electricity targets" Energy Policy 34(3): 352-364. 
Wagner, J. (2019). "Grid investment and support schemes for renewable electricity generation” Energy Journal 40(2): 195-220. Ward, K. R., R. Green, and I. Staffell (2019). "Getting prices right in structural electricity market models" Energy Policy 129(March): 1190-1206 doi:10.1016/j.enpol.2019.01.077.

Weißensteiner, L., R. Haas, and H. Auer (2011). "Offshore wind power grid connection-The impact of shallow versus super-shallow charging on the cost-effectiveness of public support" Energy Policy 39(8): 4631-4643 doi:10.1016/j.enpol. 2011.05.006.

Winkler, J., A. Gaio, B. Pfluger, and M. Ragwitz (2016). "Impact of renewables on electricity markets - Do support schemes matter?” Energy Policy 93: 157-167 doi:10.1016/j.enpol.2016.02.049. 


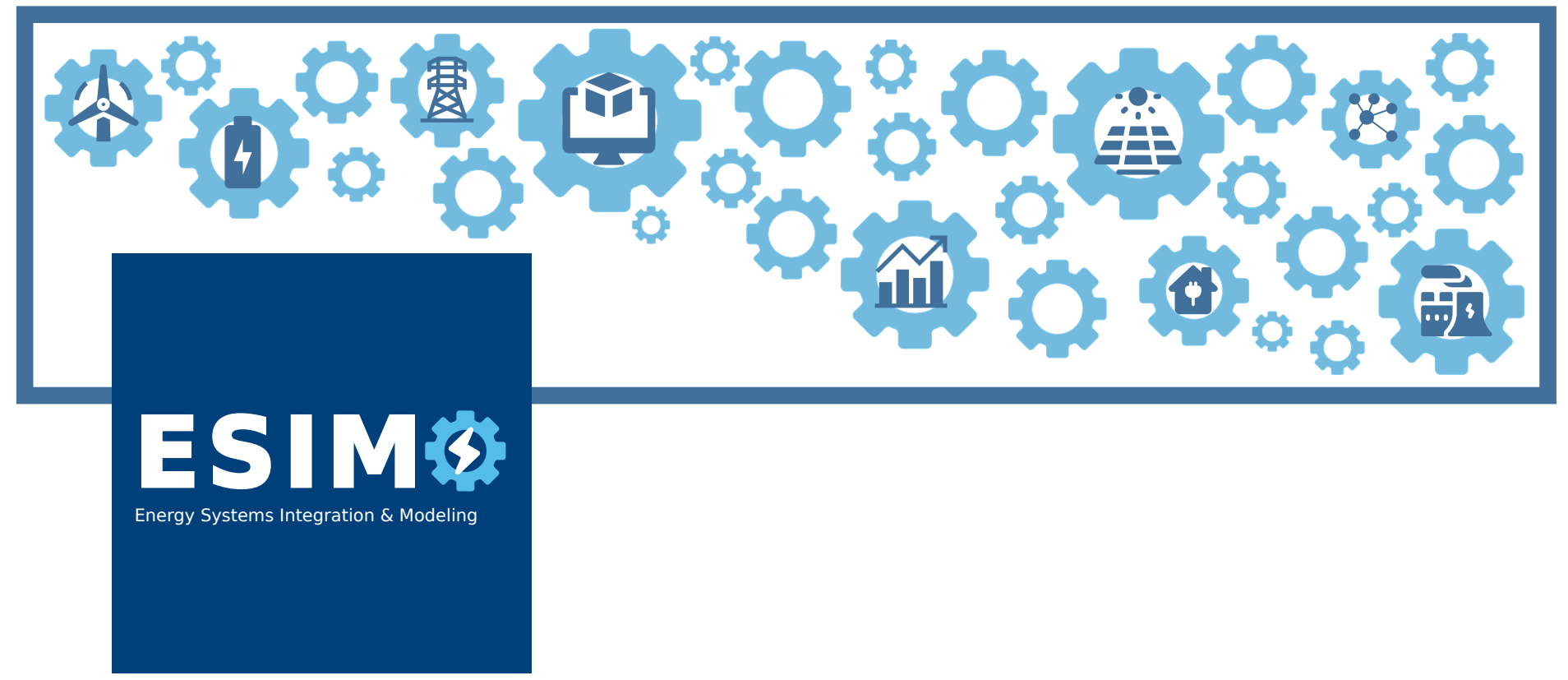

On the authors:

Jelle Meus (jelle.meus@kuleuven.be) received the M.Sc. degree in mechanical engineering in 2016, and the M.Sc. degree in international economics and management in 2018, both from the KU Leuven, Belgium. Since 2017, he has been working towards the Ph.D. degree in the Energy Systems Integration and Modeling Group at the KU Leuven and EnergyVille.

Hanne Pittomvils (hanne.pittomvils@outlook.com) received a M.Sc. degree in Mechanical Engineering in 2019 at the KU Leuven, Belgium. Currently, she is working in the field of rural electrification at the consulting company MicroEnergy International in Berlin, Germany.

Stef Proost (stef.proost@kuleuven.be) is emeritus Full Professor of Economics at the Department of Economics of KU Leuven. He teaches environmental and transport economics and has been teaching energy economics. He is also co-founder of the KU Leuven Energy Institute and Transport Mobility Leuven.

Erik Delarue (erik.delarue@kuleuven.be) received the M.Sc. degree in mechanical engineering in 2005 and the Ph.D. degree in mechanical engineering in 2009, both from the University of Leuven (KU Leuven), Belgium. Currently, he is Assistant Professor at the University of Leuven, leading the Energy Systems Integration and Modeling Group, and active in EnergyVille.

On the research group:

More information about the Energy Systems Integration \& Modeling Group can be found here. 